\title{
Baños de vapor en sitios arqueológicos zoques. Nuevos datos desde el occidente de Chiapas ${ }^{1}$ \\ Zoque Archaeological Sweatbaths. New Data from Western Chiapas
}

\author{
DAVIDE Domenici \\ Universidad de Bolonia \\ LORENZO ZURLA \\ Universidad de Messina \\ ARIanNa CAmpiani \\ Universidad de California, Merced \\ Thomas A. Lee Whiting ${ }^{\dagger}$ \\ Universidad de Ciencias y Artes de Chiapas
}

\begin{abstract}
Resumen: Las excavaciones arqueológicas llevadas a cabo por el Proyecto Arqueológico Río La Venta en la Selva El Ocote, Chiapas, han permitido investigar varios baños de vapor en sitios zoques fechados entre el Clásico Tardío-Terminal y el Posclásico Tardío; entre ellos destaca un monumental baño de vapor rectangular del periodo Clásico Tardío-Terminal, ubicado en el centro del sitio arqueológico de El Higo. Este temazcal es casi idéntico a los previamente excavados en los sitios de San Antonio, Chiapas, y Malpasito, Tabasco, ambos asociados a juegos de pelota.

Los tres baños de vapor monumentales del Clásico Tardío-Terminal pertenecen a una misma tipología relacionada con una fase de gran florecimiento cultural de los grupos zoqueanos de Chiapas y Tabasco. Sus características sugieren que una modalidad específica de juego de pelota, junto con los rituales asociados a ella, constituyó un fuerte elemento de cohesión sociopolítica de la esfera cultural zoqueana.
\end{abstract}

\footnotetext{
${ }^{1}$ Una versión resumida y preliminar de este artículo fue presentada en el Simposio "Arqueología, historia y ecología de Chiapas y Oaxaca: hacia un diálogo multidisciplinario", $54^{\circ}$ Congreso Internacional de Americanistas, Viena, Austria, 15-20 de julio de 2012. El presente texto ha sido escrito por Davide Domenici; Lorenzo Zurla, quien coordinó las excavaciones del Sector 1 de El Higo bajo la supervisión de los codirectores, es autor de los mapas que aquí se publican por vez primera; Arianna Campiani, responsable del levantamiento topográfico y del análisis arquitectónico de los edificios del sitio, ha participado en la interpretación funcional de las estructuras comentadas. El contenido del artículo es el fruto de varias discusiones entre los autores y Thomas A. Lee Whiting, sabio maestro y amigo querido que codirigió el Proyecto Río La Venta con Davide Domenici. Este artículo está dedicado a su memoria. Agradecemos a John E. Clark y a la New World Archaeological Foundation el permiso para utilizar algunas de las imágenes que aquí se reproducen.
} 
Los datos relativos a los baños de vapor posclásicos, de forma circular y a veces asociados a plataformas también circulares, son un primer acercamiento a una fase tardía de la cultura zoque, aún poco conocida desde el punto de vista arqueológico. En el presente artículo se resumen, asimismo, los datos arqueológicos relativos a otros baños de vapor hallados en el área zoque, contextualizando así los hallazgos del Proyecto Arqueológico Río La Venta, que se describen en forma sistemática por primera vez.

Palabras clave: Baño de vapor, juego de pelota, zoques, Chiapas, arqueología.

AвSTRACT: The archaeological researches carried out by the Rio La Venta Archaeological Project in the Selva El Ocote, Chiapas, led to the discovery and excavation of various sweatbaths in Zoque sites dated between the Late Classic and the Late Postclassic; foremost among them, a Late-Terminal Classic rectangular monumental sweatbath located in the site of El Higo, almost identical to those previously excavated in the sites of San Antonio, Chiapas, and Malpasito, Tabasco, both of them associated to ballcourts.

The three Late Classic monumental sweatbaths, belong to the same typology ascribable to a period of great cultural flourishing of Zoquean groups in Chiapas and Tabasco. This suggests that a specific modality of ballgame and associated ritual practices helped foster sociopolitical cohesion in the Zoquean cultural sphere. The new data regarding the Postclassic sweatbaths, circular in shape and at times associated to circular platforms, constitutes a first contribution to increase our knowledge of a still poorly understood phase of pre-Hispanic Zoquean cultural history. In this article we summarize the archaeological data on Zoque sweatbaths in order to provide a meaningful context for the findings of the Rio La Venta Archaeological Project in the Selva El Ocote, systematically described herein for the first time.

Kerwords: Sweatbaths, ballgame, Zoque, Chiapas, archaeology.

ReCEPCIÓn: 22 de mayo de 2018.

ACEPTACIÓN: 6 de julio de 2018.

DOI: 10.19130/iifl.ecm.2019.53.962.

\section{Introducción}

Si bien la literatura sobre los usos higiénicos, terapéuticos y rituales del temazcal o baño de vapor en la Mesoamérica prehispánica resulta abundante, muy limitado ha sido el estudio del uso del baño de vapor entre los pueblos zoques de la región istmeña, que se extiende desde el sur de Veracruz hasta el occidente de Chiapas incluyendo el oeste del estado de Tabasco, así como el oriente de Oaxaca. Es posible que tal escaso interés se deba al poco uso que los pueblos zoques contemporáneos hacen de una costumbre tan arraigada en la tradición mesoamericana, al contrario de sus vecinos mixes (Beals, 1945; Lipp, 1991: 170, 
181-182). Al respecto, es significativo que en la conocida síntesis etnográfica sobre los zoques escrita por George Foster en 1969 el autor haya llegado a afirmar que el temazcal es un rasgo cultural del todo faltante entre zoques y popolucas (Foster, 1969: 465; véase también Alcina, Ciudad e Iglesias, 1980: figura 7). No obstante, en la literatura etnográfica existen por lo menos un par de referencias a usos post-parto del baño de vapor entre los zoques de Rayón (Thomas, 1974a: 55) y Ocotepec (Villa Rojas, 1973: 1060).

Mas abundante, en cambio, es la evidencia de usos de baños de vapor entre los zoques de la época prehispánica. Si bien varios temazcales en sitios zoques habían sido identificados ya a partir de los años sesenta, las investigaciones llevadas a cabo por el Proyecto Arqueológico Río la Venta en el área de El Ocote, en el oeste de Chiapas, han proporcionado una buena cantidad de nuevos datos que aquí se discuten de manera sistemática por vez primera. Procederemos por lo tanto a sintetizar la información disponible sobre los diferentes tipos de temazcales prehispánicos conocidos hasta la fecha en el área zoque, integrando los datos procedentes de diferentes proyectos de investigación y de varios estudios sobre temazcales arqueológicos en Mesoamérica. Sucesivamente, nos concentraremos en una tipología específica que, en nuestra opinión, merece especial atención por la importancia que tuvo en cierto momento del desarrollo prehispánico de los zoques.

\section{El Clásico Temprano: Chiapa de Corzo y Ocozocoautla}

Uno de los baños de vapor más tempranos que ha sido identificado en el área zoque es el del Montículo 1 de Chiapa de Corzo, Chiapas, un templo funerario ubicado en el extremo sur de la plaza principal y utilizado sobre todo durante las fases Horcones e Istmo del Protoclásico (100 a.C.-250 d.C.). El edificio parece haber tenido una función residencial de élite en una de sus remodelaciones más tardías, en la fase Jiquipilas del Clásico Temprano (250-450 d-C.), y fue entonces cuando en su lado occidental se edificó un baño de vapor, descrito por Gareth Lowe y Pierre Agrinier (Lowe y Agrinier, 1960: 34-36) (Figuras 1 y 2).

El baño de vapor era una estructura cuadrada de $4.70 \times 4.50 \mathrm{~m}$, excavada al interior de construcciones anteriores y edificada con piedras cuadrangulares recubiertas por una capa de estuco, tanto en las paredes como en el piso. El piso estaba atravesado por un canal de $90 \mathrm{~cm}$ de ancho, $4 \mathrm{~m}$ de largo, y $70 \mathrm{~cm}$ de profundidad, con paredes de piedra bola estucadas; sobre un lado del edificio, el canal se conecta con un pequeño conducto de desagüe $(30 \mathrm{~cm}$ de largo; $10 \mathrm{~cm}$ de ancho) que permitía la salida del agua en exceso del edificio. El canal central, cuyo piso presenta diferentes desniveles, seguramente funcionó como lugar de recolección del agua, pero al mismo tiempo las huellas de uso demuestran que sus lados fueron utilizados como banquetas para sentarse. En su extremo interior u oriental se identificaron rastros de quemaduras y restos de cenizas y piedras bolas calcinadas que indican que allí debió de colocarse el fuego para calentar las 
piedras utilizadas para producir el vapor. Con base en las evidencias disponibles no está claro dónde se ubicaba la entrada al baño de vapor, pero Lowe y Agrinier suponen que existía un acceso en proximidad del conducto de desagüe, aunque no descartan la posibilidad de que se entrara por una abertura en el techo de material perecedero o en la parte alta de una pared.

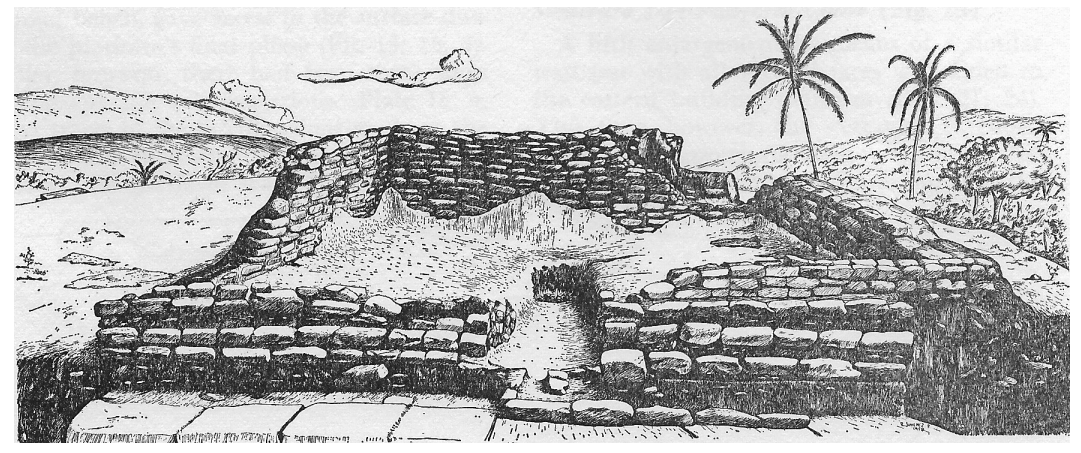

Figura 1. Reconstrucción artística del baño de vapor del Montículo 1 de Chiapa de Corzo (según Lowe y Agrinier, 1960: 34).

Otro baño de vapor fue excavado durante trabajos de salvamento del Instituto Nacional de Antropología e Historia2 en el Montículo 26 de Chiapa de Corzo, al extremo noroeste del sitio; lamentablemente la información publicada sobre el mismo es sumamente escasa (Agrinier y Clark, 2014: 92; González y Cuevas, 1998: 42, foto 13). En la terraza al norte del Montículo 13 de Chiapa de Corzo se excavaron un par de áreas empedradas con piedras bolas que fueron interpretadas como posibles baños de vapor por Alden Mason (1960: 9); no obstante, la evidencia no parece ser concluyente.

Uno más, del Clásico Temprano, fue excavado por Pierre Agrinier en el Montículo 1 de Ocozocoautla, Chiapas (Agrinier, 1992: 243-244; Agrinier, 2014: 30-35; Agrinier y Clark, 2014: 84; véase también Thomas, 1974b: fig. 43) (Figuras 3, 4 y 5). El Montículo 1, al extremo oriental del sitio, tuvo su mayor ocupación como edificio polifuncional, tanto ceremonial como residencial de élite, a partir de la fase Istmo hasta la mitad de la siguiente fase, Laguna, es decir, en un lapso poco más tardío del homónimo montículo de Chiapa de Corzo. En la tercera etapa constructiva (1-B, fase Jiquipilas), o posiblemente a finales de la anterior Etapa 1-C, un baño de vapor se edificó en la orilla oeste de la plataforma basal. La estructura medía $2.55 \times 4 \mathrm{~m}$ y tenía un acceso sobre el lado meridional: en su interior un cauce central de $80 \mathrm{~cm}$ de ancho, orientado de norte a sur, estaba flanqueado por banquetas de $30 \mathrm{~cm}$ de alto y $30 \mathrm{~cm}$ de ancho. En el extremo norte del cauce se encontraba el hogar, identificado por huellas de quemadura

\footnotetext{
${ }^{2}$ En adelante INAH.
} 

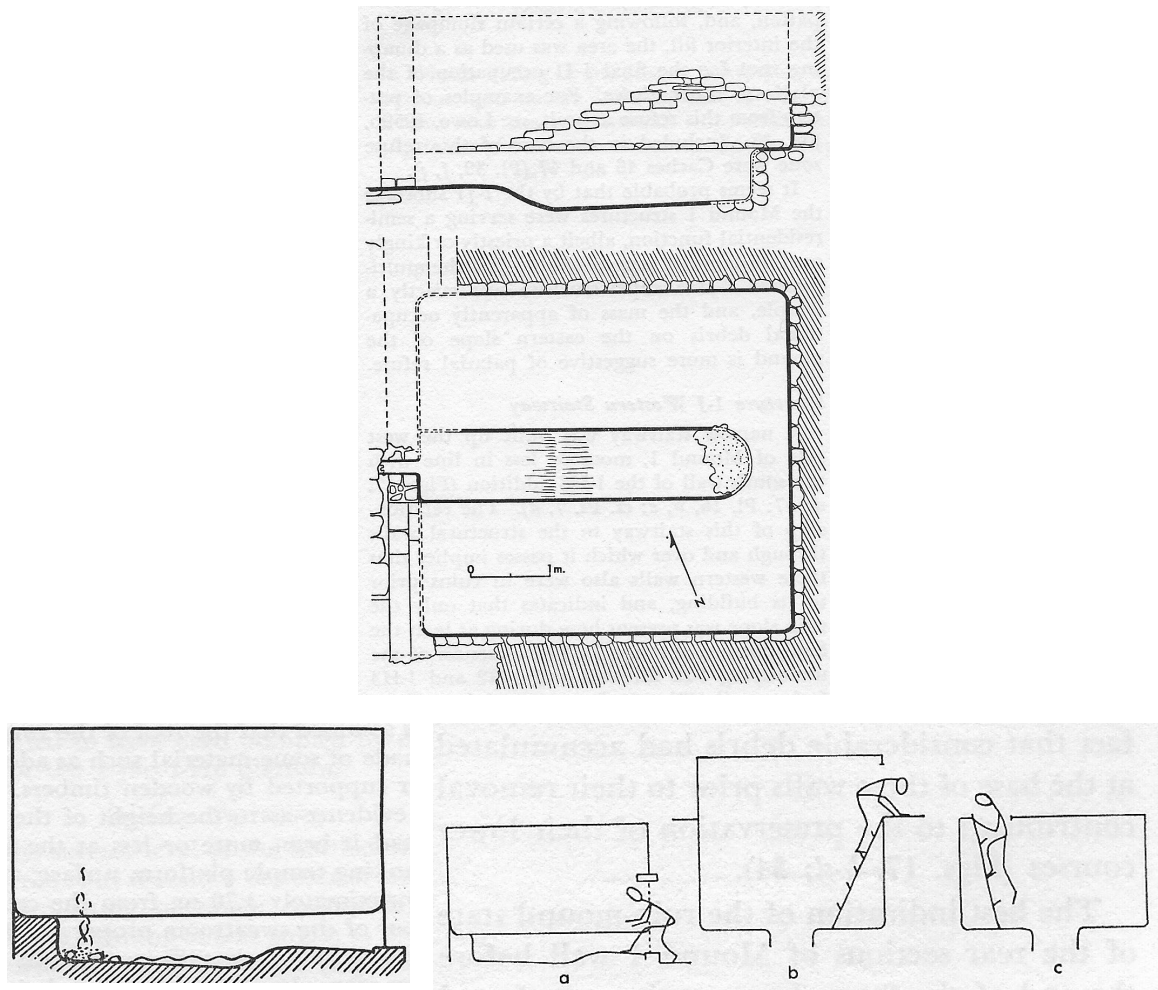

Figura 2. Plano, sección e hipótesis sobre forma de uso y acceso del baño de vapor del Montículo 1 de Chiapa de Corzo (según Lowe y Agrinier, 1960: 35).

en el estuco y restos de piedras bolas y grandes fragmentos quemados de ollas de cerámica. A cada lado del cauce central había otro espacio hundido con banquetas laterales y piso pintado de rojo. Sobre el lado oeste del edificio, un canal de desaguie de $40 \mathrm{~cm}$ de profundidad y 25 de ancho salía del edificio hacia el lado sur. Las paredes del edificio, de piedra caliza estucada, llagaban a $1.50 \mathrm{~m}$ de altura y sustentaban un techo de varas y morillos recubierto por una capa de barro de $25 \mathrm{~cm}$, a su vez cubierta por un piso de estuco de $5 \mathrm{~cm}$.

En una segunda etapa constructiva, el baño de vapor fue incorporado en la ampliación del llamado Edificio 3, que se extendió en la parte superior del baño de vapor mismo. Dos pilares de madera de $30 \mathrm{~cm}$ de diámetro se añadieron al baño de vapor para sustentar el peso del segundo piso, mientras que el acceso meridional fue sellado por un nuevo muro exterior. De esta manera, el nuevo cuarto superior, dividido en dos espacios por una pared interna, parece haber funcionado como antesala del baño de vapor, al cual se accedía probablemente a través de una entrada abierta en el piso de la antesala. Al final de la Etapa 1-B 
el temazcal fue destruido, posiblemente de manera intencional, y rellenado con escombros para sustentar un nuevo edificio superior.

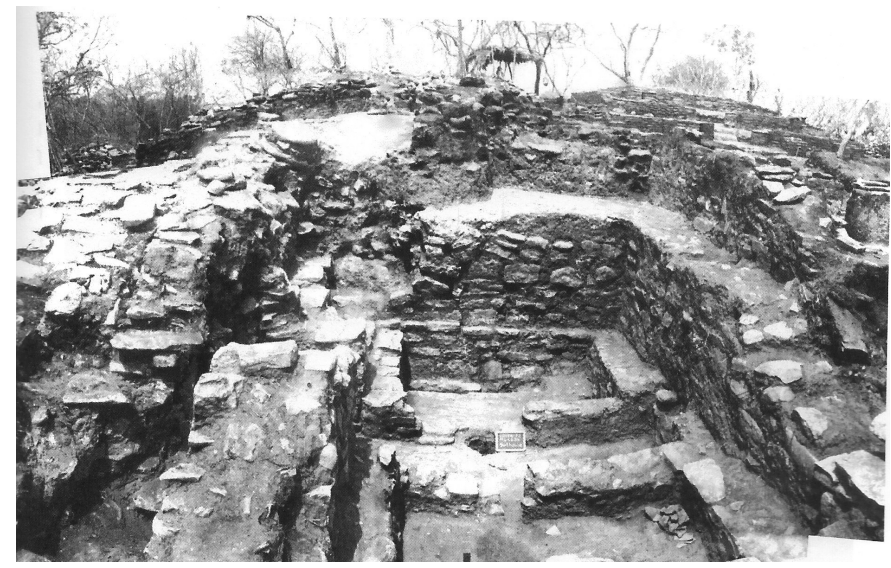

Figura 3. Vista del baño de vapor del Montículo 1 de Ocozocoautla (según Agrinier, 2014: 35).
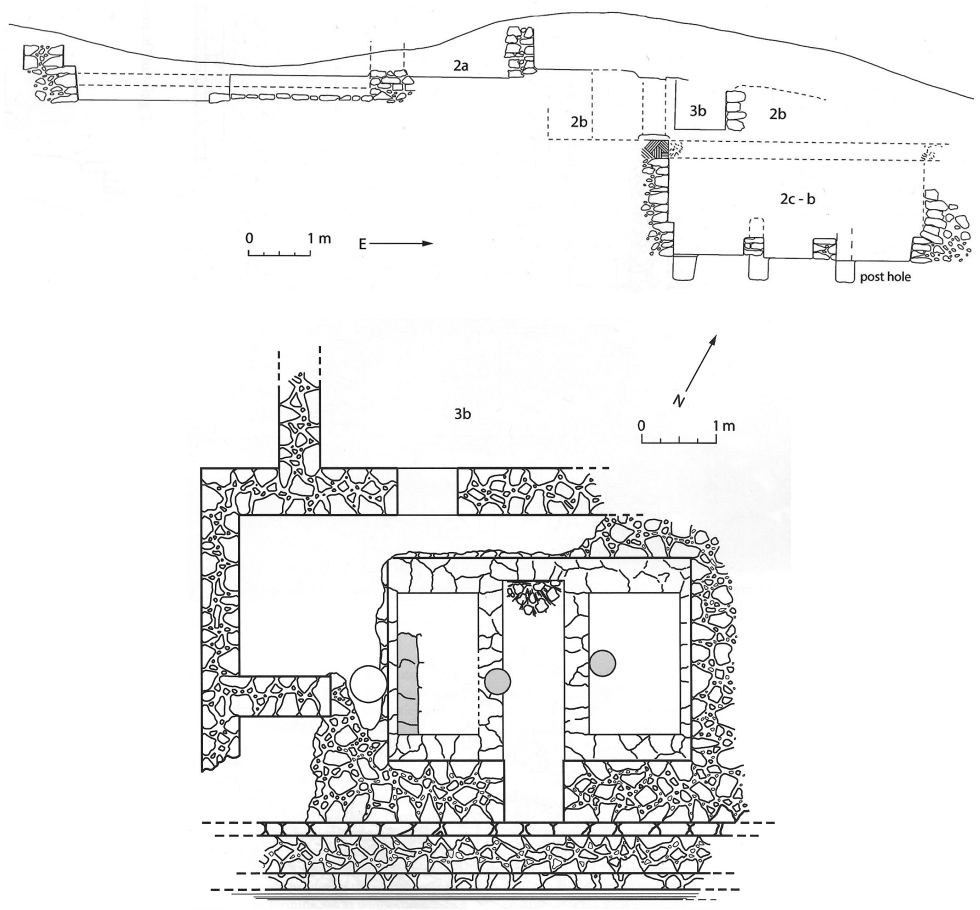

Figura 4. Plano y sección del baño de vapor del Montículo 1 de Ocozocoautla (según Agrinier, 2014: 31-33). 

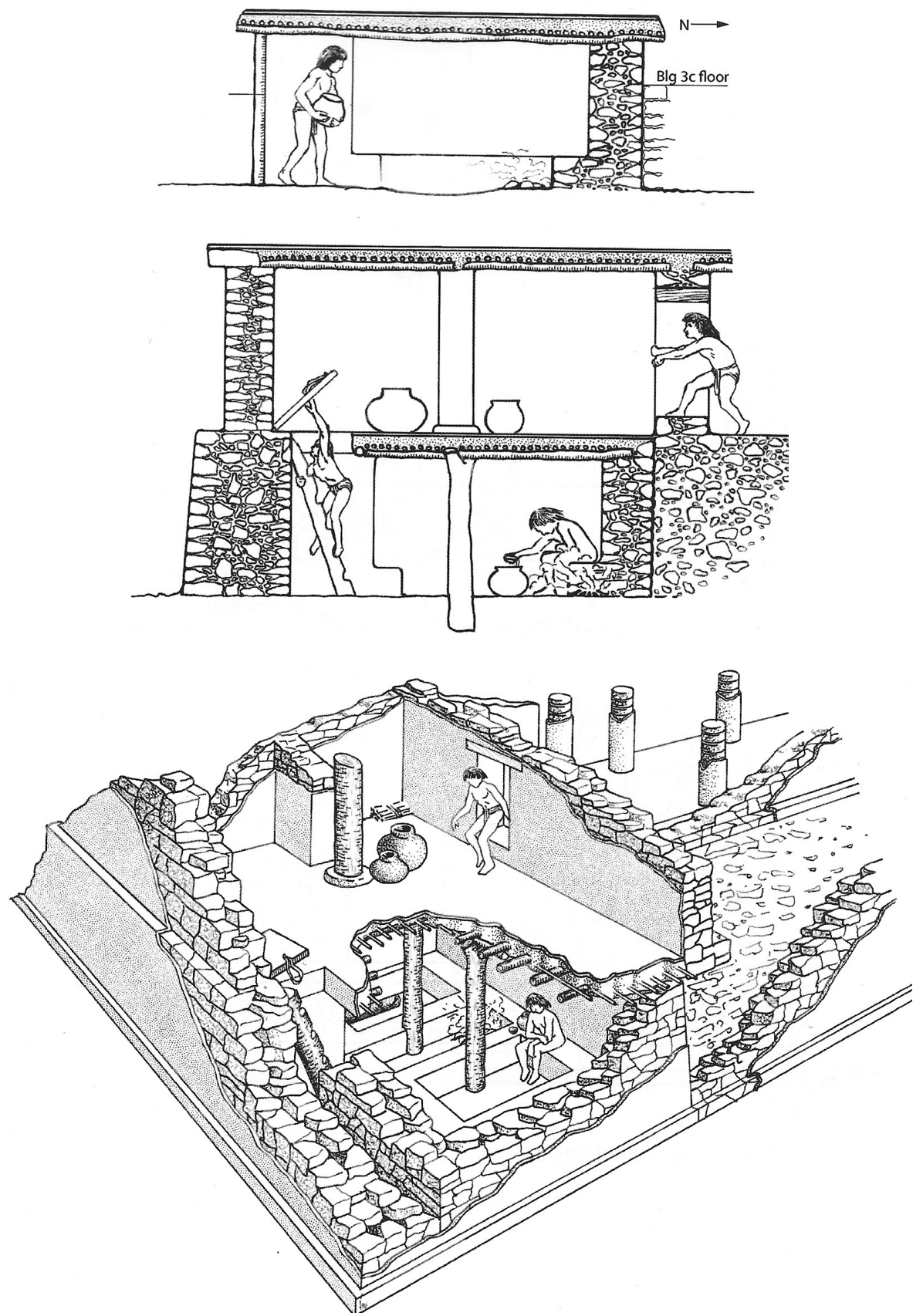

Figura 5. Hipótesis reconstructivas sobre formas de uso y accesos del baño de vapor del Montículo 1 de Ocozocoautla (según Agrinier, 2014: 31-33). 


\section{El Clásico Tardío: San Antonio, Malpasito, El Higo}

La información relativa a baños de vapor del Clásico Tardío-Terminal en el área zoque se limita a tres sitios. En ellos se han identificado tres temazcales monumentales sumamente parecidos, que constituyen el objeto principal del presente artículo.

El más conocido de estos temazcales es el que fue excavado en 1966 por Pierre Agrinier en San Antonio, Chiapas, un sitio hoy inundado y ubicado en la margen derecha del Río La Venta (Agrinier, 1966; 1969: 16-28). El baño de vapor de San Antonio (Estructura 5) se ubicaba en la cabecera occidental de la cancha para el juego de pelota, de 34 metros de largo, en la esquina sureste del área monumental del sitio (Figuras 6, 7 y 8).

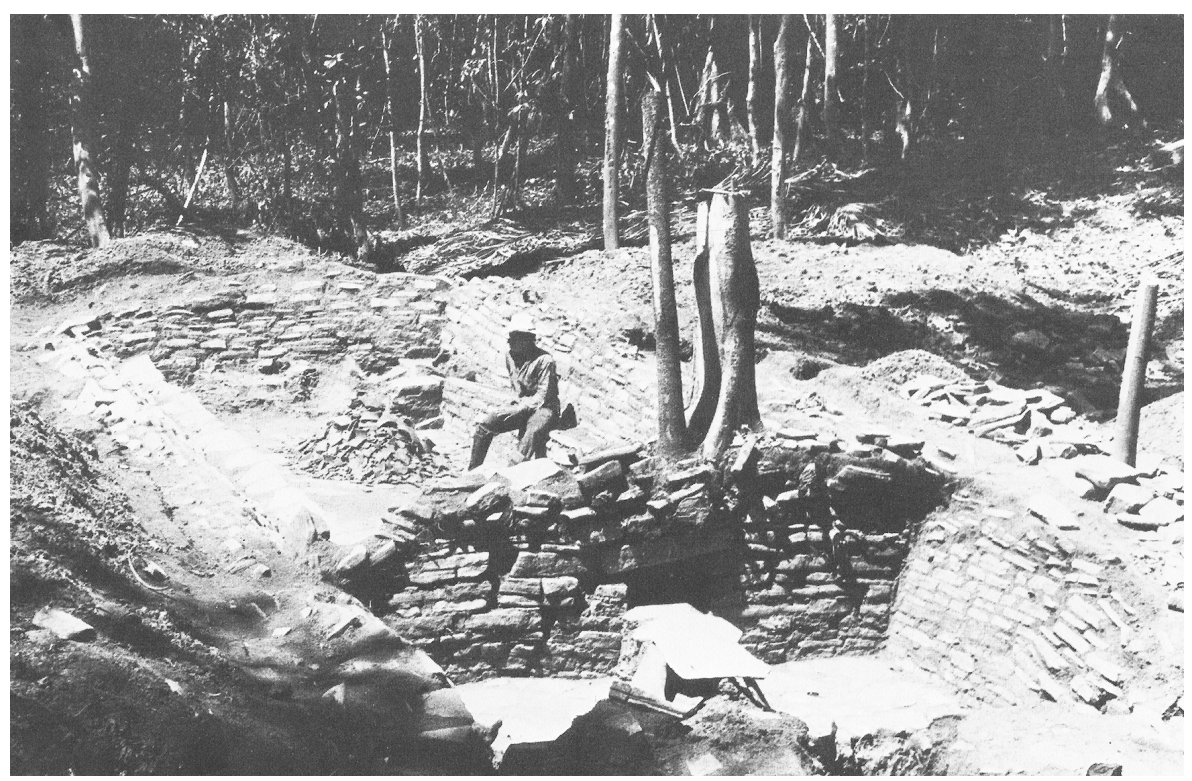

Figura 6. Vista del baño de vapor de San Antonio (según Agrinier, 1969: 24).

El baño de vapor presenta evidencias de dos etapas constructivas (5a y 5b), ambas fechadas a la fase Mechung del Clásico Tardío-Terminal (600-1000 d.C.). La más antigua, la Estructura 5a, se constituía de un espacio de 10.25 x $3 \mathrm{~m}$, dividido en dos salas, la mayor de ellas de $7.9 \mathrm{~m}$ de largo, con piso enlajado, banquetas laterales, y paredes preservadas hasta una altura de $1.60 \mathrm{~m}$; el techo presumiblemente se componía de materiales perecederos. En la esquina sureste de la sala principal, fue encontrado un canal de desagiie de $60 \mathrm{~cm}$ de ancho. Evidencias de un hornillo han sido detectadas en el lado meridional de la sala, con abundante cantidad de fragmentos de ollas quemados. En su lado norte, en 


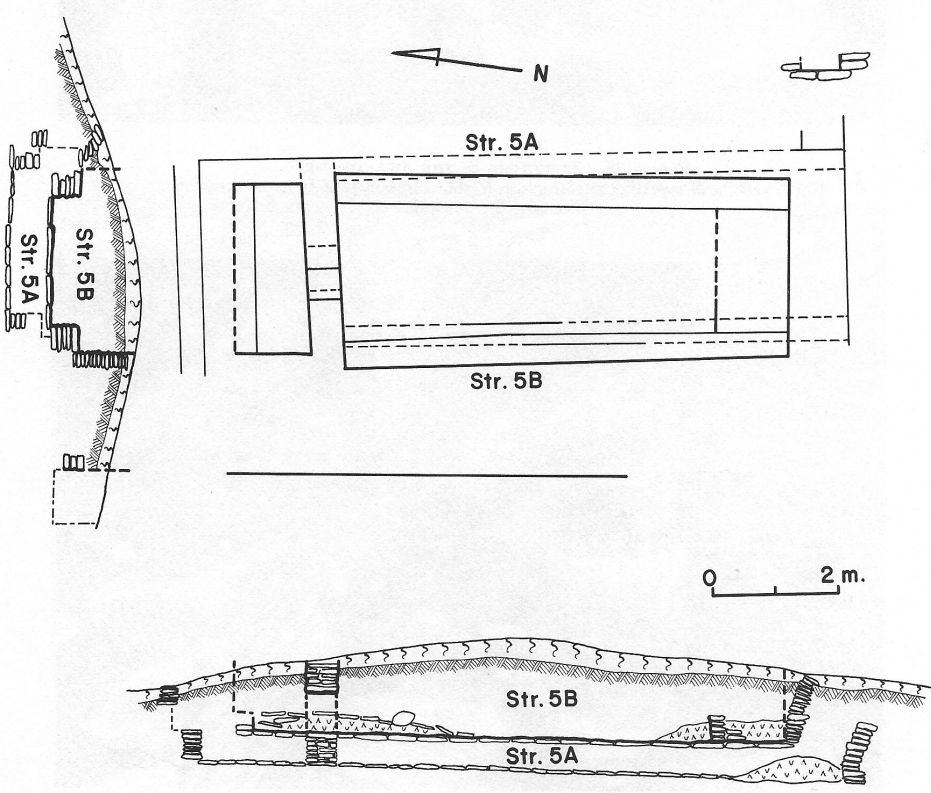

Figura 7. Plano y secciones del baño de vapor de San Antonio (según Agrinier, 1969: 21).

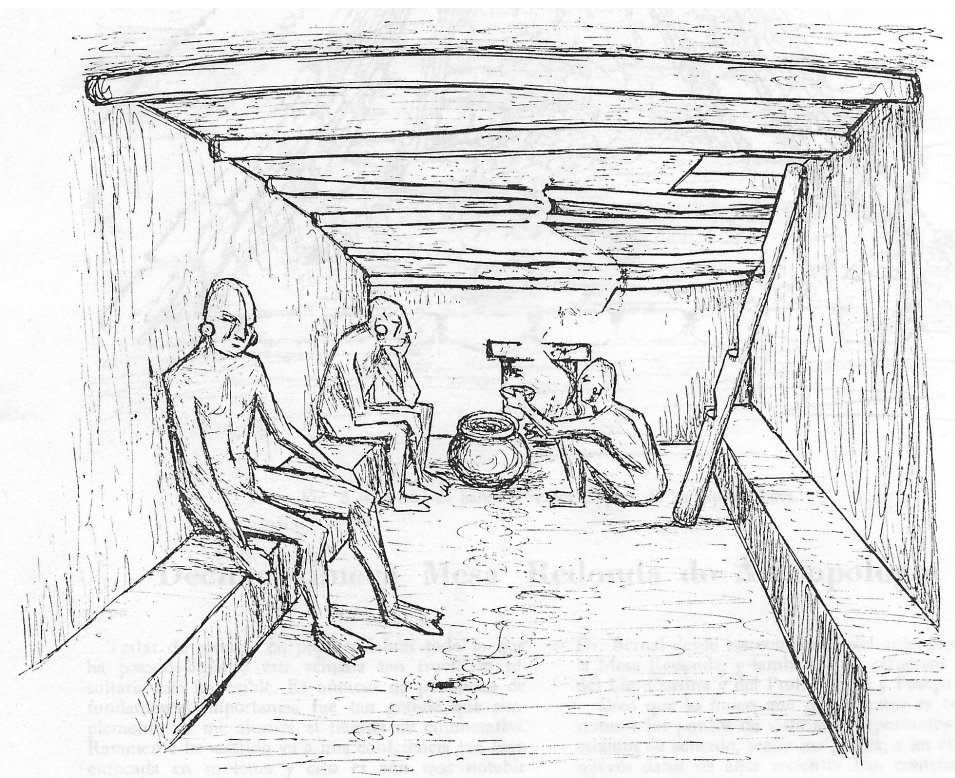

Figura 8. Hipótesis de la forma de uso del baño de vapor de San Antonio (según Agrinier, 1966). 
cambio, un muro de $60 \mathrm{~cm}$ de ancho, con un acceso de $80 \mathrm{~cm}$ de ancho, separaba la sala principal de una pequeña cámara de $1.75 \times 3 \mathrm{~m}$, con banqueta en su lado norte; según Agrinier este espacio debió funcionar como lugar para reponerse del excesivo calor de la cámara principal. Ya que no se ha encontrado algún acceso a la Estructura 5a, Agrinier supuso que se accedería por el desaguie o por el techo; con base en los datos procedentes del temazcal que nosotros excavamos en El Higo, proponemos que el acceso a la estructura se efectuara desde el techo de la pequeña cámara, que hubiera entonces funcionado como antecámara de acceso, según un patrón común en los temazcales mesoamericanos.

En una segunda etapa constructiva, la Estructura 5a fue cubierta por la Estructura $5 \mathrm{~b}$, de forma casi idéntica y ubicada $50 \mathrm{~cm}$ más arriba de la primera. Su sala principal medía $7.2 \times 3 \mathrm{~m}$, con piso enlajado y banquetas laterales de $35 \mathrm{~cm}$ de ancho y $40 \mathrm{~cm}$ de altura; Agrinier estimó que alrededor de 30 personas pudieron haberse sentado en las banquetas del baño de vapor. En el lado meridional, un muro alto como las banquetas fue edificado para formar una caja de combustión $(2.7 \times 1.2 \mathrm{~m})$. Las escasas huellas de quema sugieren que el muro fuera protegido por fragmentos de cerámica cuando se encendía el fuego; una gran acumulación de fragmentos quemados, curiosamente nunca sacados de la sala, fue encontrado en las cercanías (Figura 9).

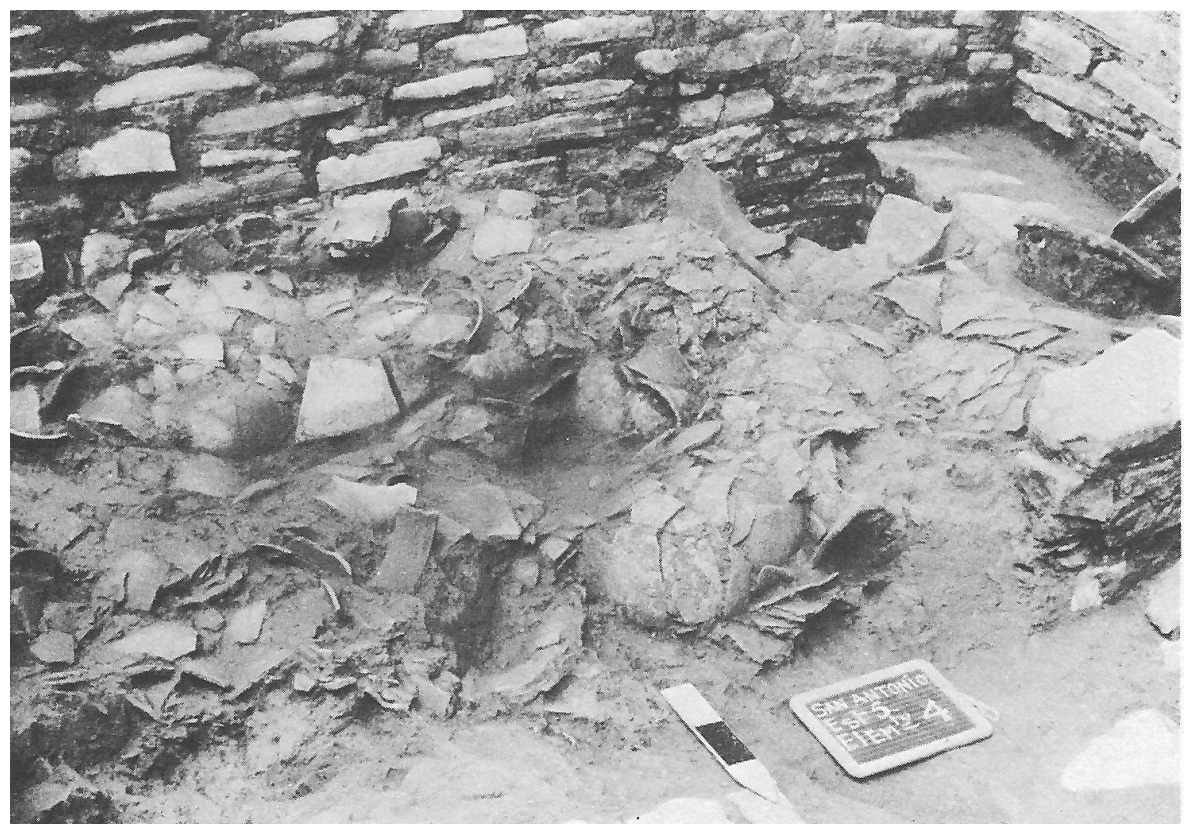

Figura 9. Material quemado y fragmentos de cerámica en la parte meridional del baño de vapor de San Antonio (según Agrinier, 1969: 25). 
Ningún desaguie, en cambio, fue encontrado en la Estructura 5b. Una antecámara $(2.7 \times 1.25 \mathrm{~m})$ parecida a la de la Estructura 5 a fue edificada también en la estructura 5b, con banqueta en el lado norte y acceso a la sala principal en el lado sur. En un segundo momento de utilización, esta antecámara fue convertida en cámara de combustión, ampliando su lado norte y utilizando el viejo acceso como lugar para alimentar el fuego a partir de la sala principal (Figura 10). Si la antecámara hubiera funcionado como acceso, en este segundo momento otro acceso debería haber sido abierto en el techo de la sala principal. A lo largo del tiempo esta cámara de combustión se rellenó con desechos, por lo que se empezó a prender el fuego en la esquina noroeste de la sala principal, como demuestra otra acumulación de residuos cerca de la cual fue encontrada una olla íntegra (Figura 11).

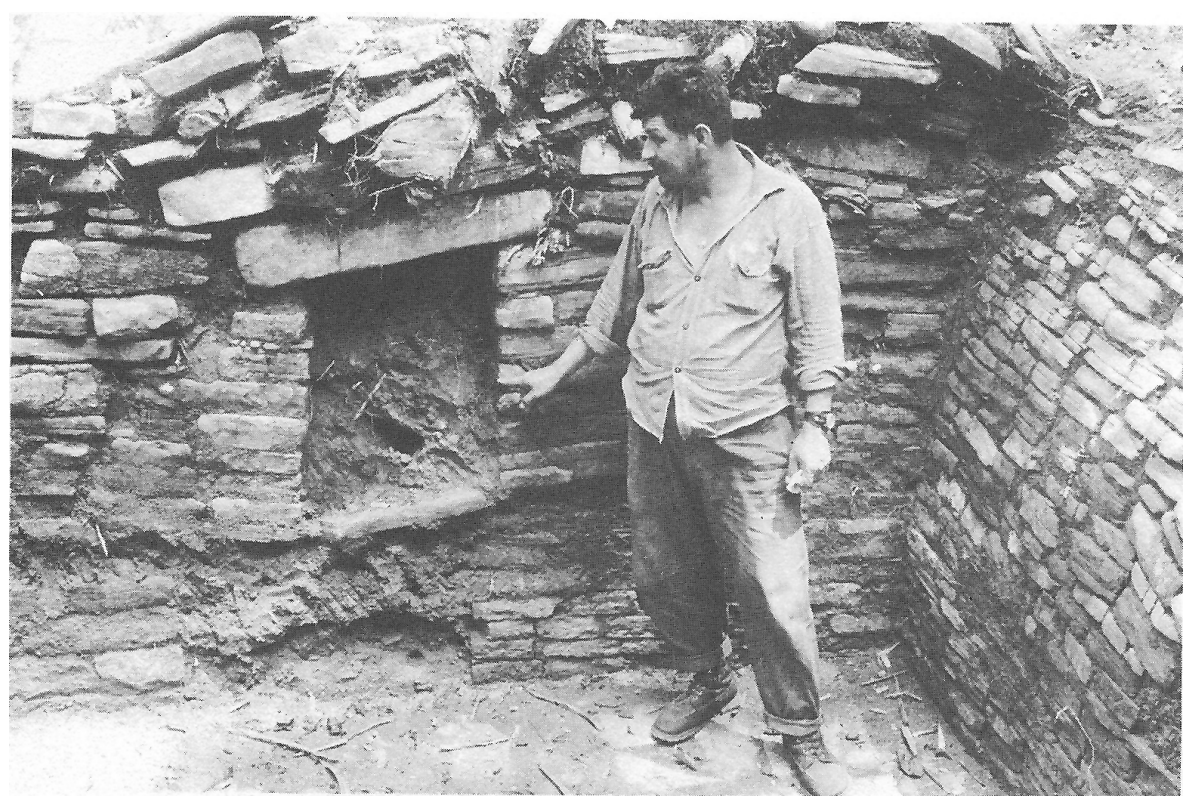

Figura 10. Viejo acceso remodelado para alimentar la cámara de combustión del baño de vapor de San Antonio (según Agrinier, 1969: 26).

El gran baño de vapor de San Antonio permaneció como un caso único en Mesoamérica por sus dimensiones, hasta que otro ejemplo análogo fue excavado en 1993 en el sitio de Malpasito, Tabasco (Cuevas, 1994, 2004), en las últimas estribaciones de la Sierra Norte de Chiapas. Las excavaciones del Programa de Rescate Integral de Zonas Arqueológicas de Tabasco del INAH sacaron a la luz una cancha de juego de pelota en forma de T, de 34 metros de largo, con un cabezal abierto y uno cerrado. El juego de pelota se ubica en la parte inferior del área 


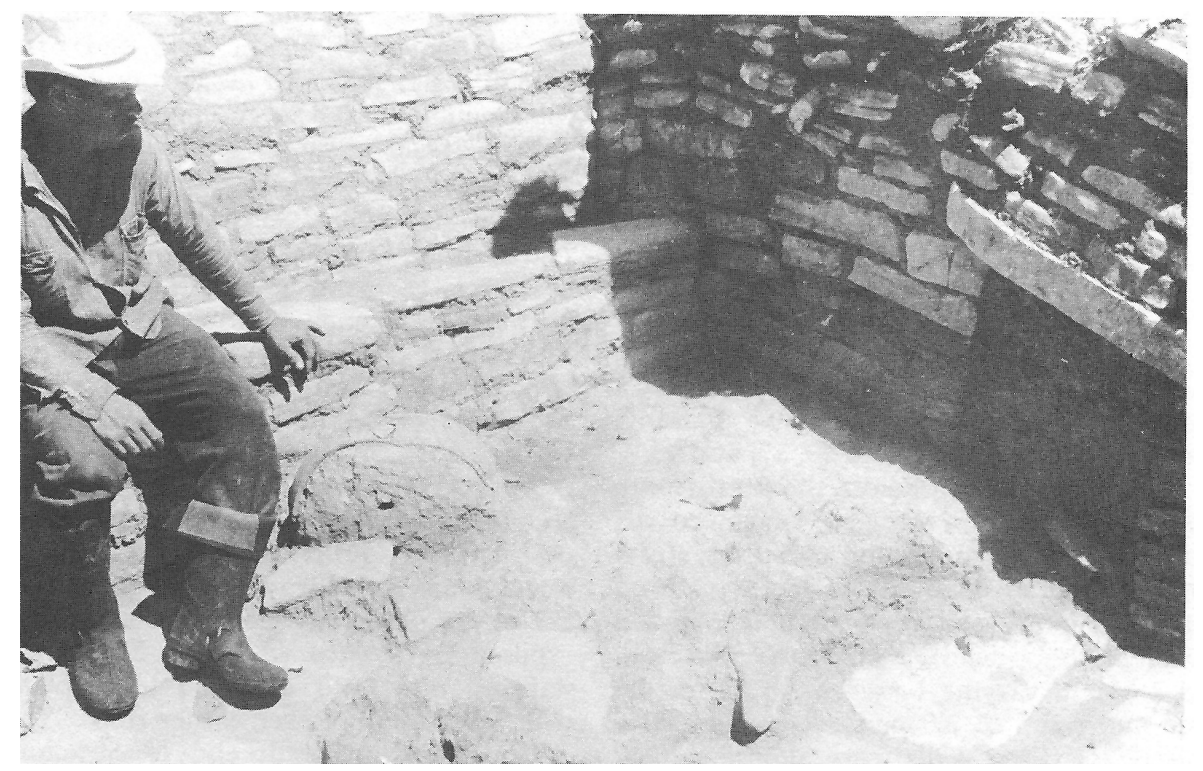

Figura 11. Restos de fuego y olla íntegra sobre el piso del baño de vapor de San Antonio, utilizado después de haber rellenado completamente la cámara de combustión (según Agrinier, 1969: 27).

cívico-ceremonial del sitio, y ha sido fechado para la fase Mechung del Clásico Tardío-Terminal. Encima del peralte de la terraza que delimita el lado meridional de la cancha, al nivel de la plaza principal del sitio, fue ubicada la Estructura 18, es decir, el baño de vapor que aquí nos interesa (Cuevas, 2004: 53-54). Se trata de un edificio semisubterráneo de 11.40 × $3.80 \mathrm{~m}$, dividido en tres espacios contiguos: en el extremo noroeste se ubica una antecámara de acceso con escalinata de nueve escalones, al centro la sala de vapor con banquetas laterales $(33-41 \mathrm{~cm}$ de altura; 40-43 cm de ancho) y, al extremo suroeste, una cámara de combustión separada por un muro de la sala principal (Figura 12).

Las paredes se conservan hasta una altura variable entre 1.67 y $1.92 \mathrm{~m}$. Las banquetas de la sala de vapor sustentan dos pilastras que funcionan como contrafuertes. Cuevas Reyes estima que las banquetas pudieron haber tenido una capacidad de 20 personas, 10 por cada lado. Partes del techo de material perecedero, colapsado debido a un incendio, fueron encontradas sobre el piso enlajado del extremo oeste de la sala, y fragmentos de barro cocido indican que las paredes tuvieron un repello de barro. Escasos fragmentos de ollas fueron encontrados entre el material carbonizado en las mismas áreas. Según Cuevas Reyes, este material quemado es fruto del colapso de la techumbre, y las ollas fragmentadas debieron ser utilizadas para contener el agua necesaria para producir el vapor.

El cuarto en el extremo oeste se utilizaba como cámara de combustión, el muro que la separaba de la sala de vapor se calentaba y el agua para producir 
vapor se arrojaba directamente sobre éste; en el artículo publicado desafortunadamente no se describe qué tipo de material se encontró al interior de la cámara de combustión. Un elemento sumamente interesante del baño de vapor de Malpasito es que frente a su escalinata de acceso (Figura 13) fueron excavadas tres ofrendas de vasijas colocadas en una caja de mampostería o debajo de lajas de piedra, según un patrón común en el contemporáneo sitio de San Isidro (Cuevas, 2004: 55).

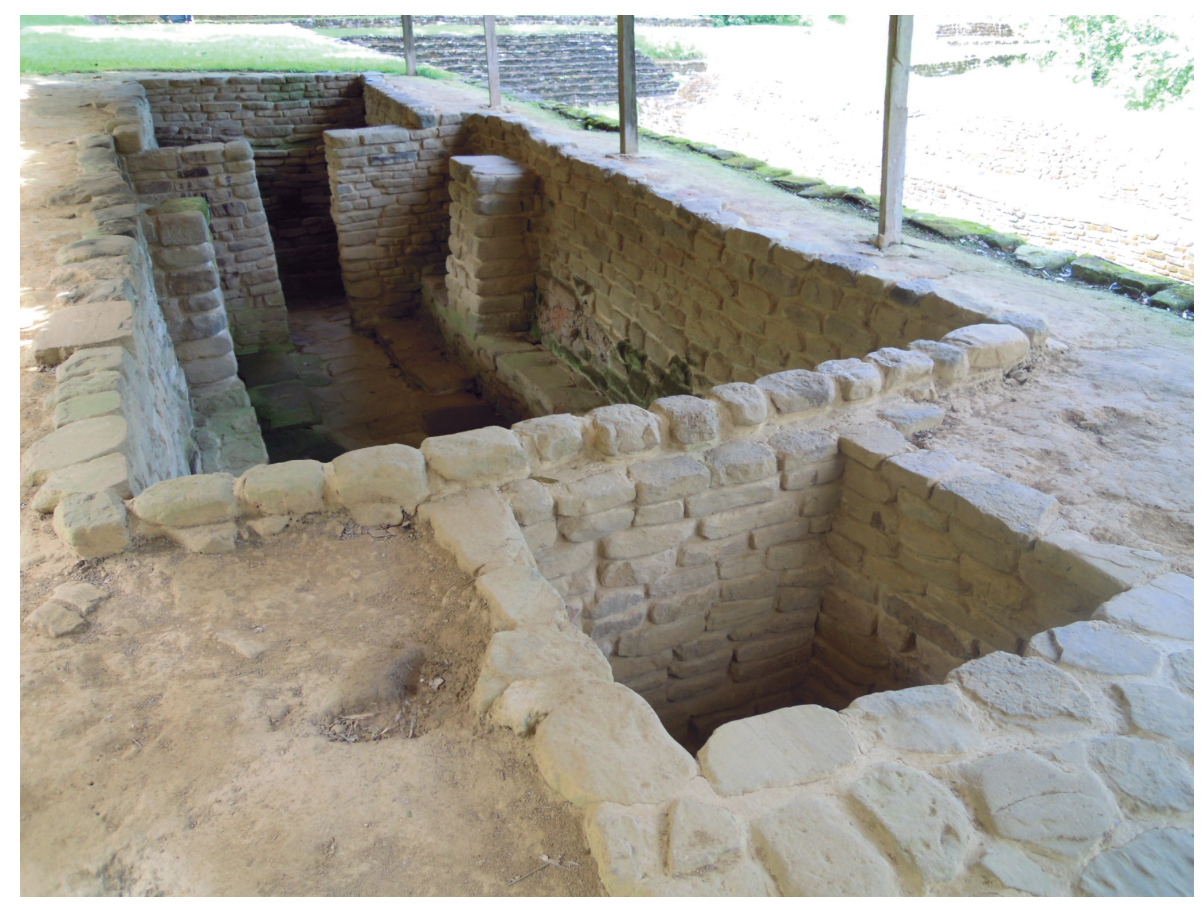

Figura 12. Vista general del baño de vapor de Malpasito; nótese la cámara de combustión en primer plano y el cuarto con escalinata de acceso al fondo.

En 2003, durante las excavaciones que el Proyecto Arqueológico Río La Venta llevó a cabo en el sitio de El Higo, en la selva El Ocote, Chiapas, se halló una tercera estructura sumamente parecida a las que acabamos de describir (Domenici, 2006; Zurla, 2003, 2009). Llamada Estructura 38sub, se ubica en la terraza norte del sitio, exactamente a espaldas de la Estructura 1 que domina la plaza principal (Figuras 14 y 15).

El baño de vapor, fechado como los de San Antonio y Malpasito a la fase Mechung del Clásico Tardío-Terminal, fue encontrado profundizando la excavación de la Estructura 38, una plataforma residencial perteneciente a un conjunto habitacional del Posclásico Tardío. Aunque el baño de vapor 38 sub aparentemente 


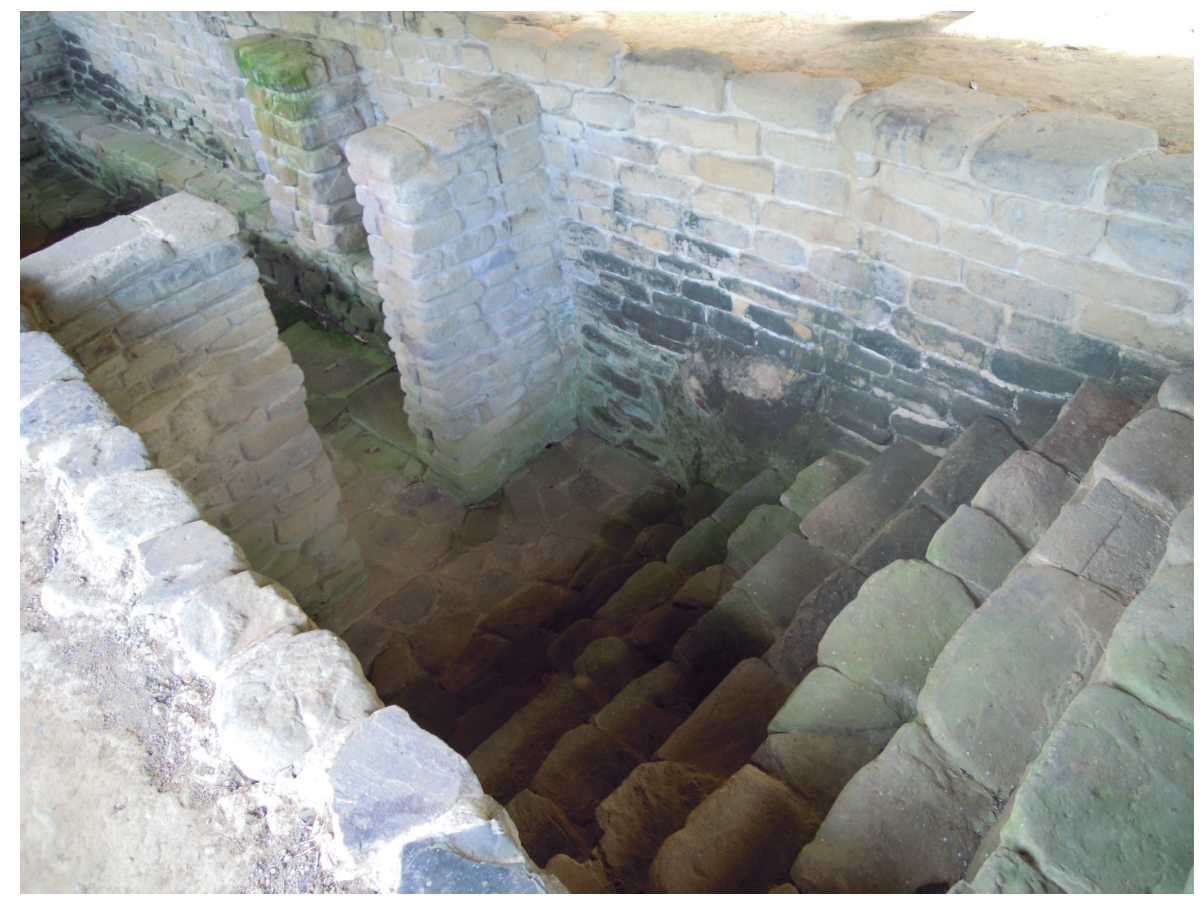

Figura 13. Escalinata de acceso del baño de vapor de Malpasito.

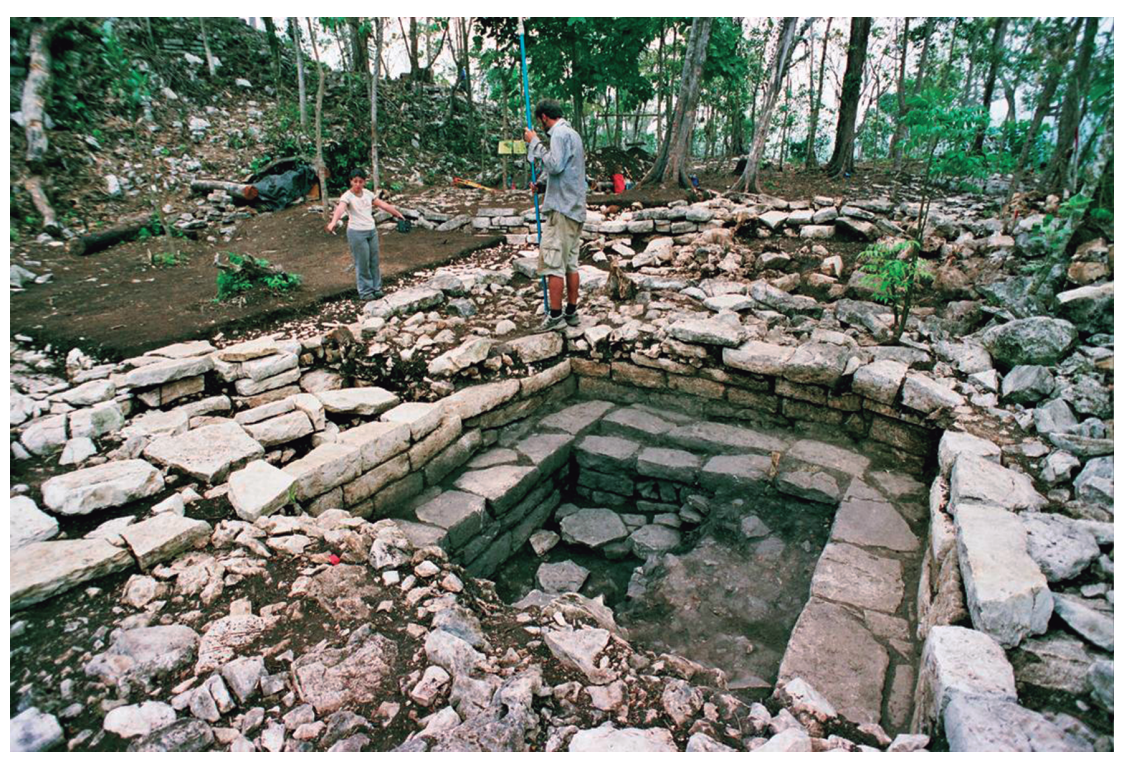

Figura 14. El baño de vapor de El Higo durante la excavación. Al fondo, sobre el lado izquierdo, se nota el desplante del basamento sobre el cual surge la Estructura 1 del sitio. 
no está asociado a un juego de pelota, la disposición espacial de las estructuras visibles en la superficie sugiere que una cancha para el juego de época clásica pudiera estar ubicada entre el talud basal de la misma terraza norte y la Estructura 31, hoy cubierta por estructuras posclásicas, así como ocurre en muchas estructuras del sitio. El juego de pelota de tipo abierto y con un lado constituido por el talud de una terraza sería entonces parecido al contemporáneo juego de pelota del sitio de "Población Malpasito" (Cuevas, 2004: 48). Si éste es el caso, la ubicación espacial del baño de vapor de El Higo respecto al juego de pelota sería sumamente parecida a la del temazcal de Malpasito.

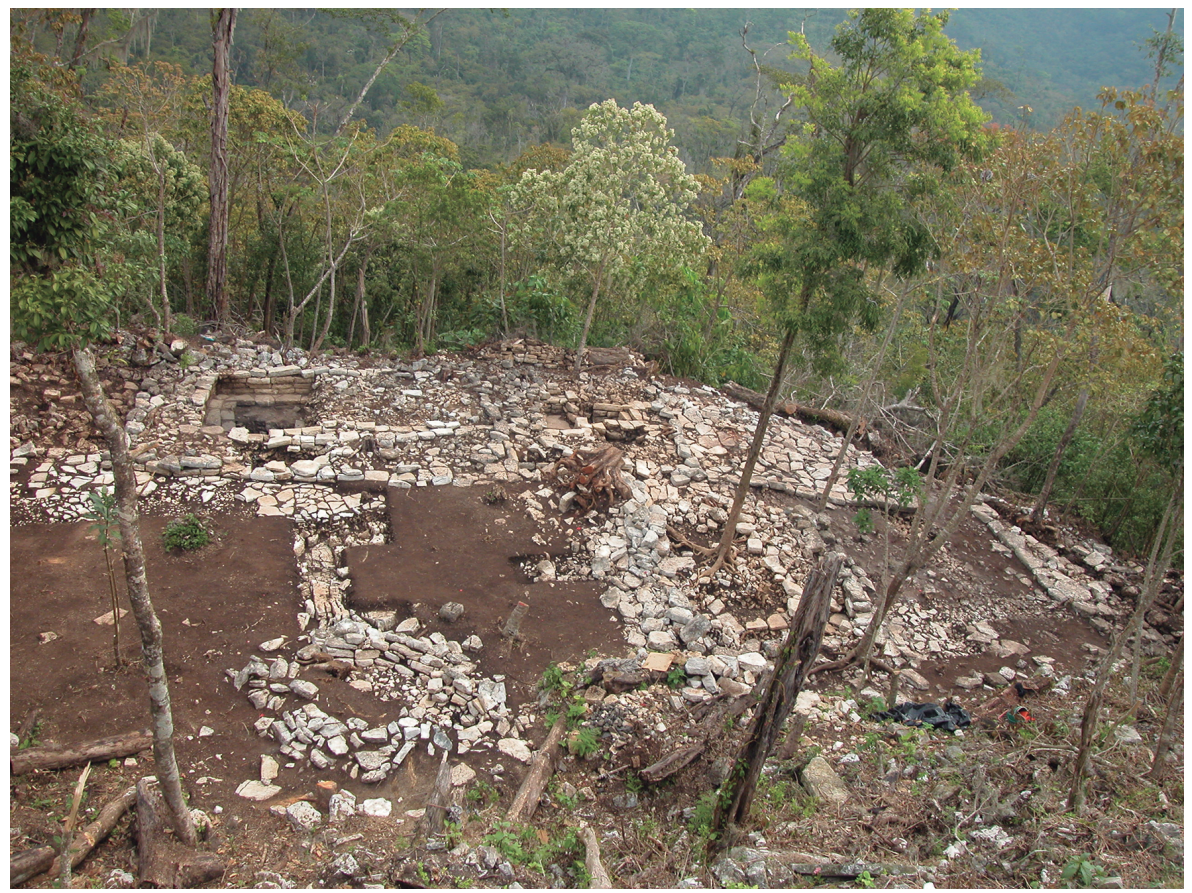

Figura 15. Vista de la terraza norte del sitio de El Higo con el baño de vapor monumental del Clásico Tardío, al fondo, y el baño de vapor circular del Posclásico Tardío, en primer plano.

El baño de vapor se compone de una sala semisubterránea de $9.30 \times 2.95 \mathrm{~m}$, edificada con bloques careados de caliza, piso enlajado y banquetas sobre los lados norte, sur y oeste (Figuras 16, 17 y 18). El lado este de la sala, en cambio, se conecta a través de un acceso con un pequeño espacio cuadrangular sobre cuyo lado este se observa un escalón de acceso, lo cual indica que dicho espacio funcionó como antecámara de acceso (Figura 19). El largo total de la Estructura 38sub, incluyendo la antecámara, llega así a los $11.49 \mathrm{~m}$. La observación de la banqueta sobre el lado corto occidental de la sala sugiere que ésta se añadió en 
un segundo momento a la estructura original, ya que el muro oeste de la sala sigue detrás de la banqueta. Las limitaciones de tiempo no permitieron desmontar la banqueta ni extender la excavación hacia el oeste, para verificar si una cámara de combustión anexa pudiera ubicarse sobre este lado (así como ocurre en Malpasito) y si un posible acceso interno hubiera sido tapado por la banqueta.

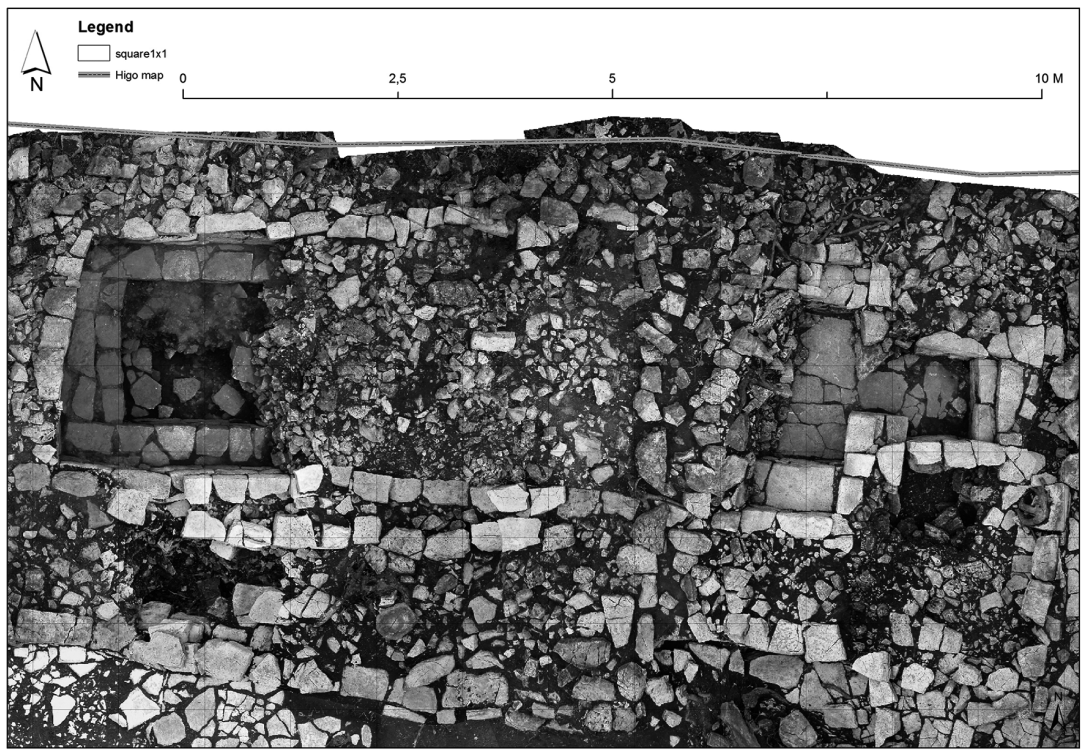

Figura 16. Fotomosaico vertical del baño de vapor de El Higo; en la parte central de la cámara se observa parte del relleno posclásico.

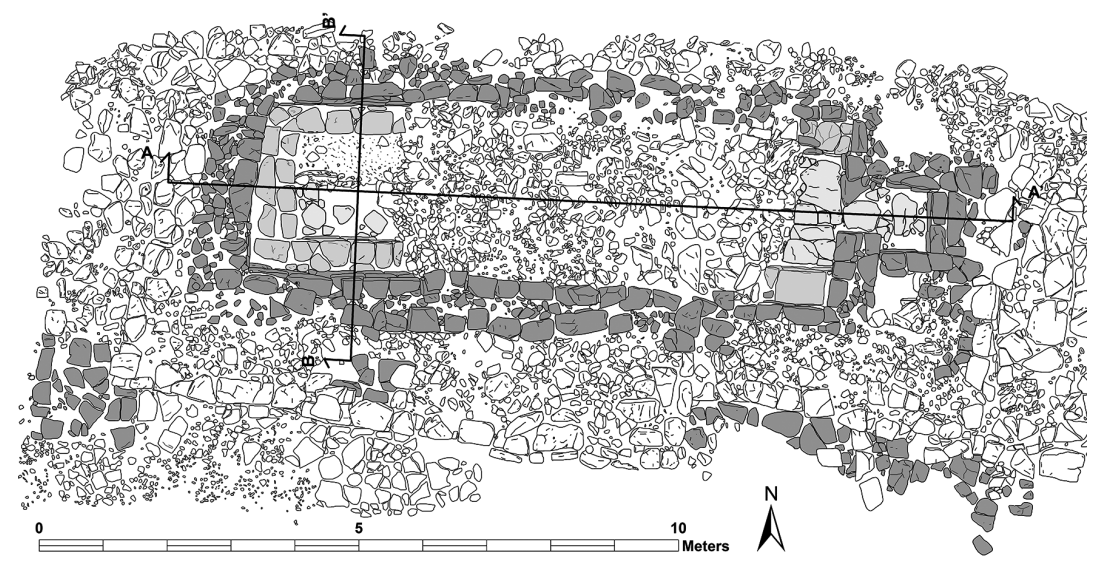

Figura 17. Plano del baño de vapor de El Higo; en tonos de grises las estructuras del Clásico Tardío. 

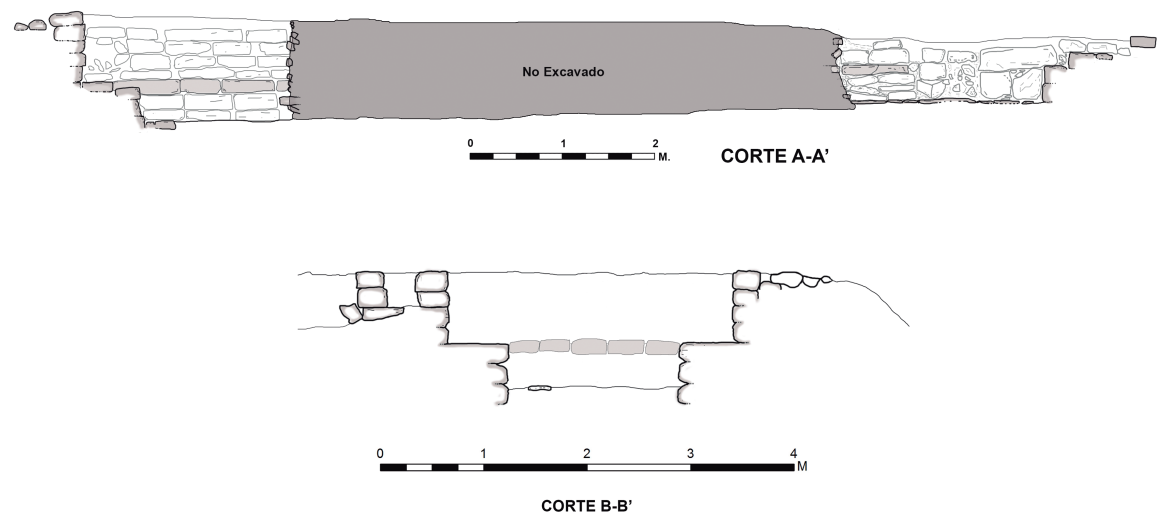

Figura 18. Secciones del baño de vapor de El Higo.

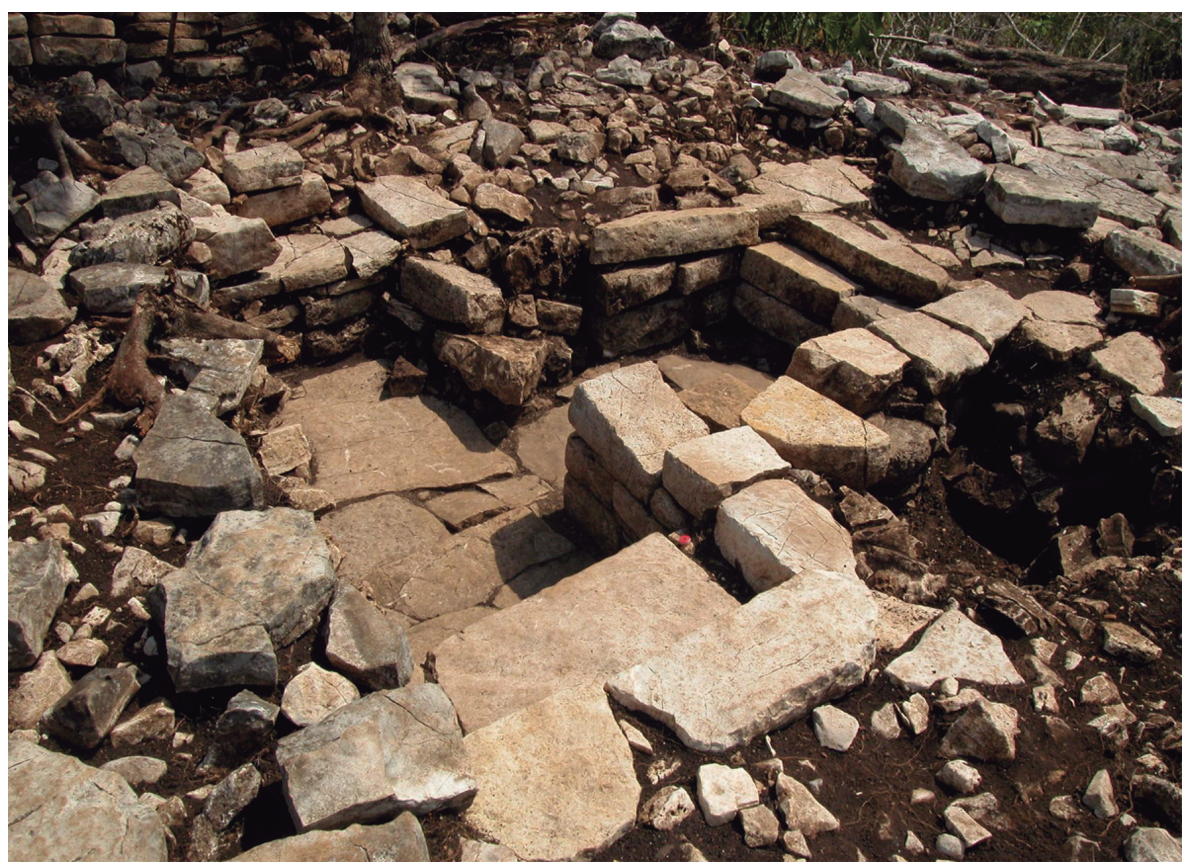

Figura 19. Acceso del baño de vapor de El Higo. 
Sin embargo, todo el lado occidental del baño de vapor fue encontrado con relleno de desechos de combustión y de fragmentos de ollas quemados, de una forma del todo parecida al caso de San Antonio (Figura 20); la observación de la estratigrafía indica que el relleno se divide en dos capas diferentes (US29 y US31), posiblemente asociadas a dos fases de utilización del temazcal. Es evidente que en ambas capas los fragmentos cerámicos fueron depositados cuidadosamente, ya que se encontraron grupos de hasta nueve fragmentos uno dentro del otro; en tres metros cúbicos de depósito se encontraron 28,379 kilos de cerámica.

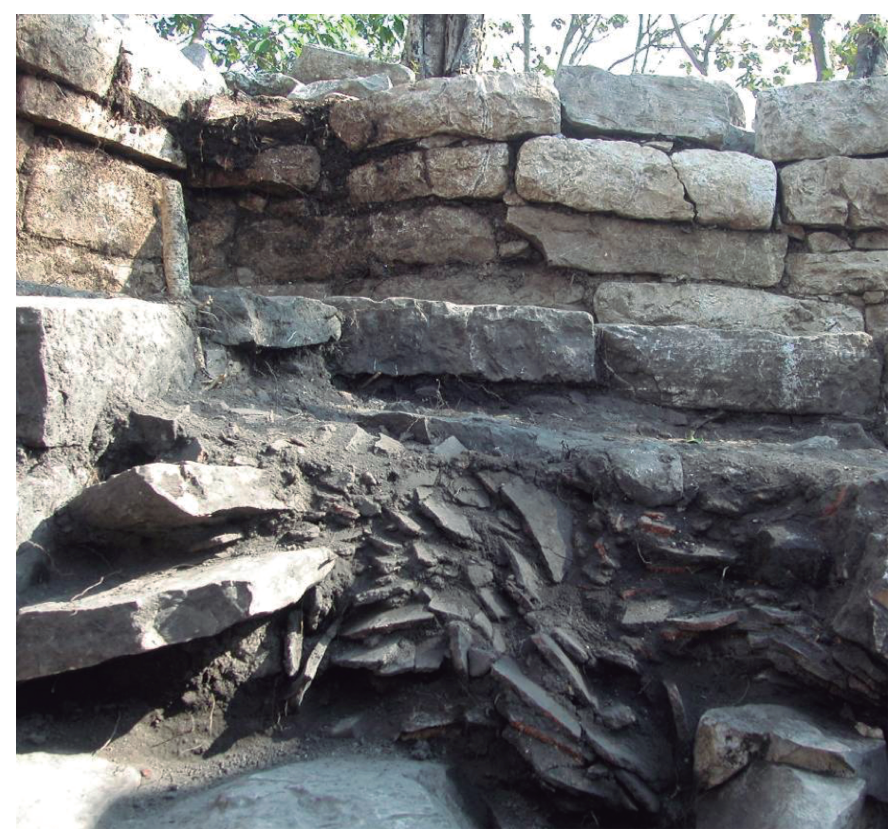

Figura 20. Restos de material quemado y fragmentos de cerámica en el interior de la cámara del baño de vapor de El Higo.

La deposición de la capa de fragmentos cerámicos quemados sugiere que, por lo menos en algún momento, el fuego para calentar el material cerámico se encendía directamente en el piso de la sala principal. Así como en el caso de la Estructura 5b de San Antonio, no se detectaron canales de desagüe, pero la excavación parcial de la estructura, limitada a sus extremos este y oeste, no permite afirmarlo con seguridad.

En el momento en que la terraza norte fue convertida en un área residencial en la época Posclásica, todo el espacio subterráneo -todavía visible no obstante un periodo de abandono del sitio- fue artificialmente rellenado con escombros para obtener una base sobre la cual levantar las plataformas posclásicas (véase Figura 16). Un hacha pulida de piedra verde se depositó en el piso del baño de 
vapor, posiblemente como ofrenda de terminación, mientras que en el lado oeste de la cámara el relleno se apoyó directamente encima de la capa de material quemado. Al construirse la Plataforma 38, los muros oeste y sur del temazcal se aprovecharon como bases para levantar los muros que delimitaban subdivisiones internas. Las remodelaciones posclásicas cortaron los muros del baño de vapor al nivel del suelo, así que no tenemos evidencias de su altura original y podemos solamente imaginar una altura parecida a la de San Antonio y de Malpasito, es decir de aprox. 1.60-1.70 m. La presencia de argamasa con huellas de elementos vegetales en la parte baja del relleno indica que el baño de vapor tuvo originalmente un techo de material perecedero cubierto por una capa de argamasa, posiblemente estucada, así como ocurrió en los casos de San Antonio y Malpasito.

\section{El periodo Posclásico}

Siendo el conocimiento arqueológico de las fases posclásicas del área zoque todavía muy somero, no sorprende que en la literatura no se encuentren referencias a baños de vapor de esta época. Sin embargo, en nuestras investigaciones en la Selva El Ocote identificamos una tipología de estructuras circulares bajas, típica de la ocupación del Posclásico Tardío. Estas construcciones, de unos $3 \mathrm{~m}$ de diámetro aproximadamente, pudieran haber funcionado como baños de vapor, aunque dicha interpretación debe todavía considerarse como una hipótesis de trabajo, que necesitaría ser verificada a través de más excavaciones sistemáticas. Tales estructuras circulares, algunas de las cuales fueron también detectadas por Matthew Stirling y Frederick Peterson en sus reconocimientos en el área meridional del cañón del Río La Venta (Peterson, 1961; Clark, 2014: 238), están usualmente asociadas con plataformas y conjuntos residenciales (en sitios como El Higo, El Maculiz, Unidad Modelo), pero a menudo se encuentran aisladas o en grupos, como única forma de reocupación tardía de sitios clásicos (sitios de López Mateos, El Cafetal, La Ceiba), o en la cumbre de alturas aisladas de difícil acceso (El Gigantal), lo cual sugiere un uso tanto doméstico como ceremonial. Un elemento común a la mayoría de las estructuras circulares es la presencia de una protuberancia irregular, de función desconocida, sobre su lado externo. El sitio donde tales estructuras han sido mayormente estudiadas -y donde presentan una mayor variedad formal- es El Higo. Como parte del mencionado conjunto residencial posclásico que cubrió el baño de vapor monumental clásico, por ejemplo, se edificó una estructura circular (Estructura 40) en el extremo meridional del patio principal (véase Figura 15).

Una tipología mas compleja es representada por dos ejemplos en la plaza principal del sitio: se trata de una estructura circular como las anteriores, pero asociada a una plataforma circular empedrada de mayor tamaño, caracterizada por pilares monolíticos que delimitan un acceso. Tal tipología está ejemplificada por la Estructura 6-7 en la parte alta de un complejo residencial sobre patio en 
el extremo meridional de la plaza (Figura 21), así como por la estructura 7-12, asociada a un importante complejo de plataformas en la plaza central (Figuras 22 y 23).

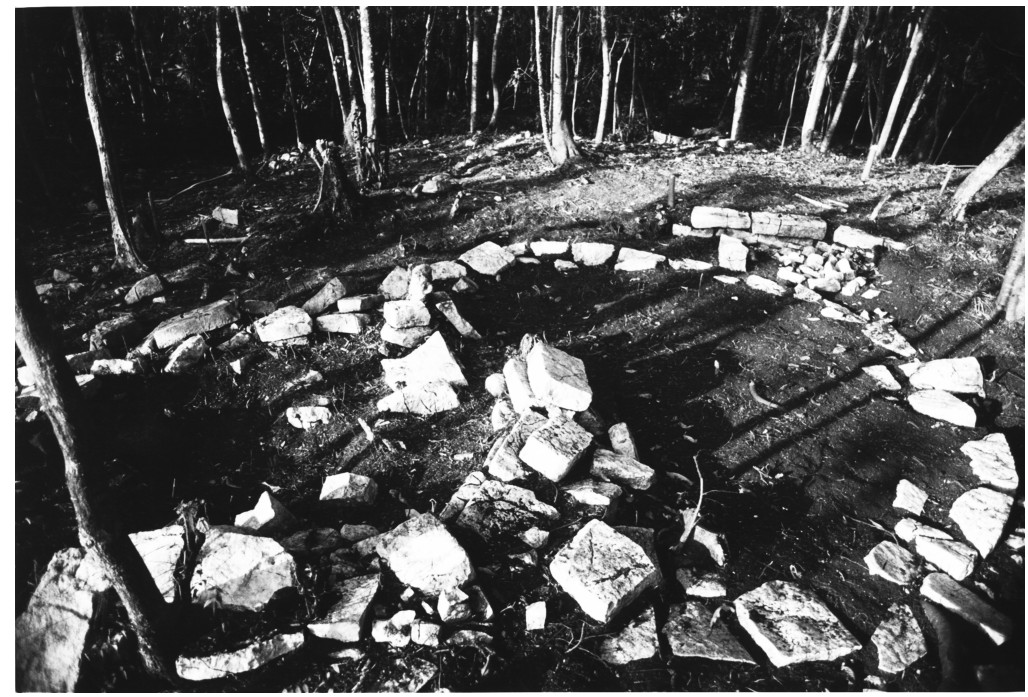

Figura 21. Estructura circular (Estructura 6, a la izquierda) y plataforma circular asociada (Estructura 7, a la derecha), El Higo.

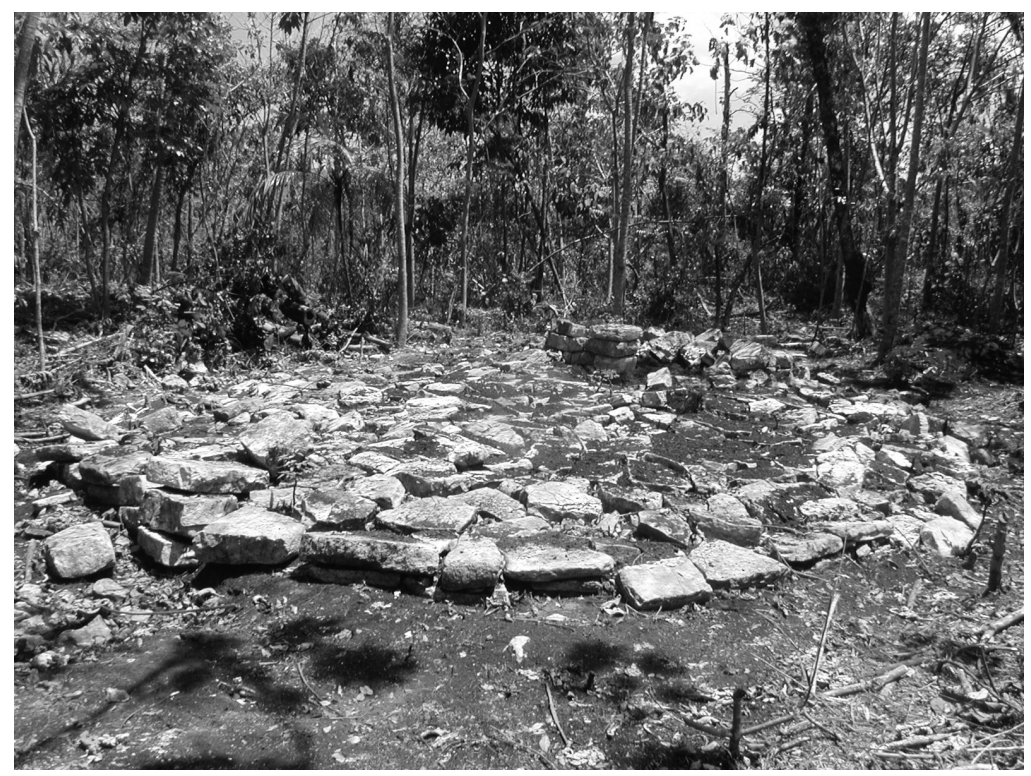

Figura 22. Estructuras 7 (al fondo) y 12 (en primer plano), El Higo. 


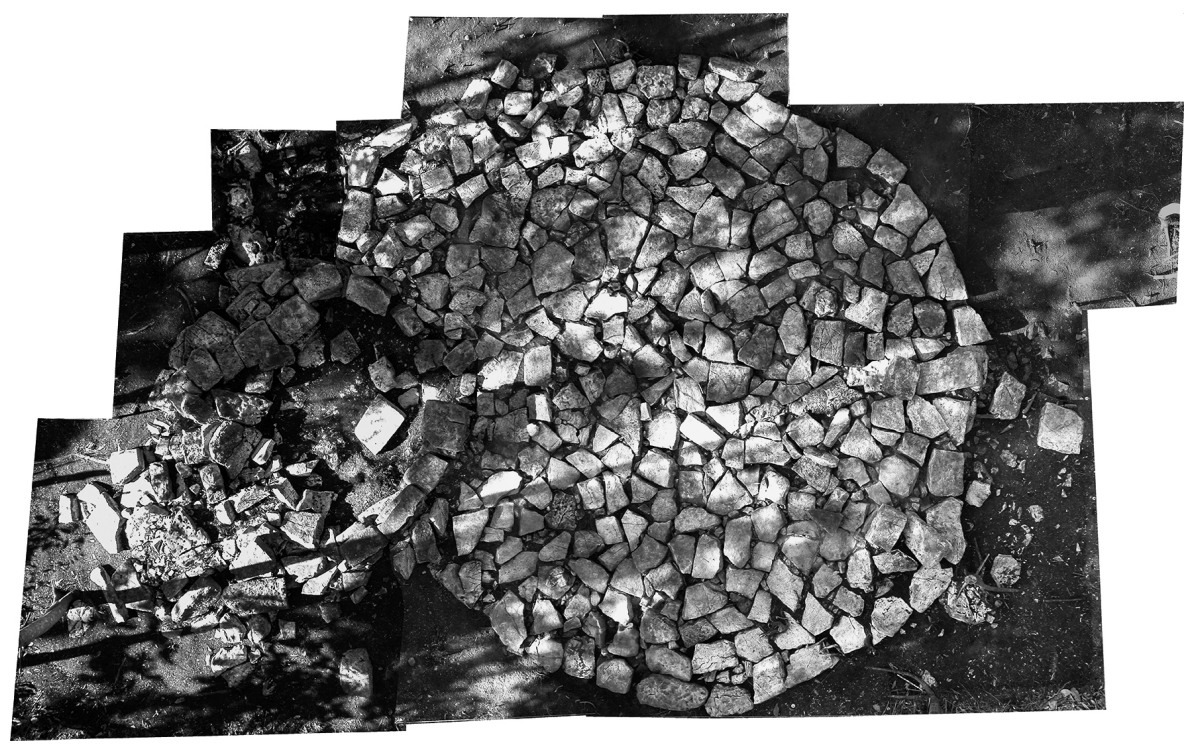

Figura 23. Fotomosaico vertical de las Estructuras 7, a la izquierda, y 12, a la derecha.

La excavación de dos de las mencionadas estructuras circulares, una por cada tipología, lamentablemente no ha llevado a interpretaciones concluyentes: en la Estructura 40 se encontraron grandes fragmentos de una olla que según análisis químicos de residuos contuvo una bebida fermentada, ${ }^{3}$ mientras que la excavación de las Estructuras 7-12, además de sacar a la luz abundante cantidad de fragmentos de incensarios sobre el perímetro de la plataforma circular, reveló que la estructura tuvo un piso estucado y pintado de rojo. Ninguna evidencia de material quemado se encontró en las dos construcciones.

La posible interpretación de las estructuras circulares como baños de vapor deriva por lo tanto de la comparación con estructuras circulares parecidas que existen en otras regiones mesoamericanas, como, por ejemplo, las de la Mixteca (Finsten et al., 1996) o la Estructura C-75b excavada en el sitio posclásico maya de Los Cimientos de las Margaritas, Chiapas (Lowe y Álvarez, 2007), en donde se asocia a un conjunto residencial. Se trata de una estructura ovalada baja de piedra que tuvo probablemente un techo en domo y su piso estuvo estucado y pintado de rojo, un elemento que comparte tanto con la Estructura 7-12 de El Higo como con el temazcal de Ocozocoautla, descrito con anterioridad. Si la interpretación es correcta, deberíamos pensar que las estructuras circulares de la región de El Ocote funcionaban como bases para edificios con techo de material perecedero en forma de domo, en los cuales se introducían piedras u otros

\footnotetext{
${ }^{3}$ Alessandra Pecci, comunicación personal.
} 
elementos previamente calentados al exterior de la estructura. La asociación de la mayor parte de las estructuras circulares con conjuntos residenciales sugiere un uso prevalentemente higiénico, aunque la presencia de una olla con bebida fermentada pueda sugerir también usos de tipo ritual, los cuales son, en cambio, más probables para aquellas estructuras asociadas a plataformas circulares, así como para las ubicadas en lugares aislados, donde pudieran haber tenido lugar ceremonias de purificación y aislamiento. Cabe subrayar que pequeños baños de vapor circulares fueron frecuentes en la Mesoamérica posclásica y que la misma forma sigue siendo una de las más comunes entre los baños de vapor modernos descritos en la literatura etnográfica de México. La diferencia formal entre los baños de vapor clásicos rectangulares de Chiapa de Corzo, Ocozocoautla, San Antonio, Malpasito y El Higo y los circulares posclásicos parece ser el reflejo local de dos diferentes tradiciones detectadas previamente en el área maya, donde una tradición de baños de vapor cuadrangulares de élite - limitada al periodo Clásico- se opone a una más larga tradición vernácula de baños de vapor circulares en forma de domo (Helmke, 2005: 67; Helmke y Awe, 2010).

\section{Discusión}

Los datos hasta aquí resumidos, y su comparación con la literatura arqueológica sobre los baños de vapor (véanse, entre otros, Mason, 1935; Carrasco, 1946; Cresson, 1938; Satterthwaite, 1952, 2005; Taladoire, 1975; Ichon, 1977; Alcina, Ciudad e Iglesias, 1980; Servain, 1986; Andrews IV y Andrews V, 1980; McKee, 1997; Groark, 1997: 9; Alcina, 2000; Child y Child, 2000, 2001; Gaxiola, 2001; Hammond y Bauer, 2001; Child, 2005, 2006, 2007; Ortiz Butrón, 2001, 2005; Helmke y Awe, 2010; Matarredona, 2014; Benavides y Ojeda, 2015; Koszkul y Źrałka, 2017), indican que el uso del temazcal en el área zoque se difundió en época relativamente tardía respecto a otras regiones mesoamericanas como el área maya, donde hay ejemplos arqueológicos de baños de vapor a partir del Preclásico Medio (Andrews IV y Andrews V, 1980; Hammond y Bauer, 2001; Koszkul y Źrałka, 2017).

Esto, por supuesto, no implica que en épocas anteriores en el área zoque no se utilizaran baños de vapor, sino que el uso de materiales perecederos en su construcción no dejara huella en el registro arqueológico. Los dos ejemplos más tempranos, en Chiapa de Corzo y Ocozocoautla, a pesar de algunas diferencias estructurales, presentan muchos elementos comunes: ambos asociados a conjuntos residenciales de élite, tienen una dimensión variable entre los 10 y los $21 \mathrm{~m} 2$ y presentan un cauce central cuyos muros laterales funcionaron como banquetas para sentarse.

Su asociación con edificios residenciales de gran tamaño que son ampliados, en donde el temazcal se incluye como parte del nuevo programa arquitectónico, y su fechamiento a la fase Jiquipilas - es decir, al momento de apogeo de la cultura zoque del oeste de Chiapas en el Clásico Temprano- sugieren que las élites zo- 
ques de la época habrían introducido el uso del baño de vapor posiblemente con función tanto higiénica como ritual. Es preciso subrayar que probablemente en la percepción prehispánica no existiera una tajante división entre función higiénica, ritual y médica del baño de vapor. Si el baño de vapor fue introducido en el Clásico Temprano en el área zoque, esto pudiera bien haber sido consecuencia de la larga interacción tenida con los grupos mayas en la cuenca del Grijalva desde el Preclásico Tardío (Clark y Pye, 2011).

Curiosamente, no hay evidencia de baños de vapor asociados a conjuntos residenciales a lo largo del Clásico Tardío-Terminal, mientras que dicha asociación se da nuevamente en el Posclásico, cuando las pequeñas construcciones circulares detectadas en El Ocote y aquí tentativamente identificadas como baños de vapor podrían haber desempeñado, otra vez, un papel tanto higiénico como ritual. Esta última función sería mayormente evidente en los ejemplos dotados de plataforma circular, en donde, por lo menos en un caso, se ha asociado con el uso de incensarios.

De sumo interés es la difusión en el Clásico Tardío-Terminal de la tipología de baños de vapor monumentales, representada por los casos de San Antonio, Malpasito y El Higo. El parecido entre los tres ejemplos descritos es evidente: todos ellos son de tamaño único en Mesoamérica (con áreas totales variables aproximadamente entre los 28 y los $44 \mathrm{~m} 2$; compárese con datos en Matarredona, 2014: 30 ), por lo menos en dos casos están asociados a canchas para el juego de pelota (Figuras 24 y 25), fueron dotados de una antecámara de acceso y los largos espacios con banquetas laterales debieron hospedar grandes grupos de individuos.

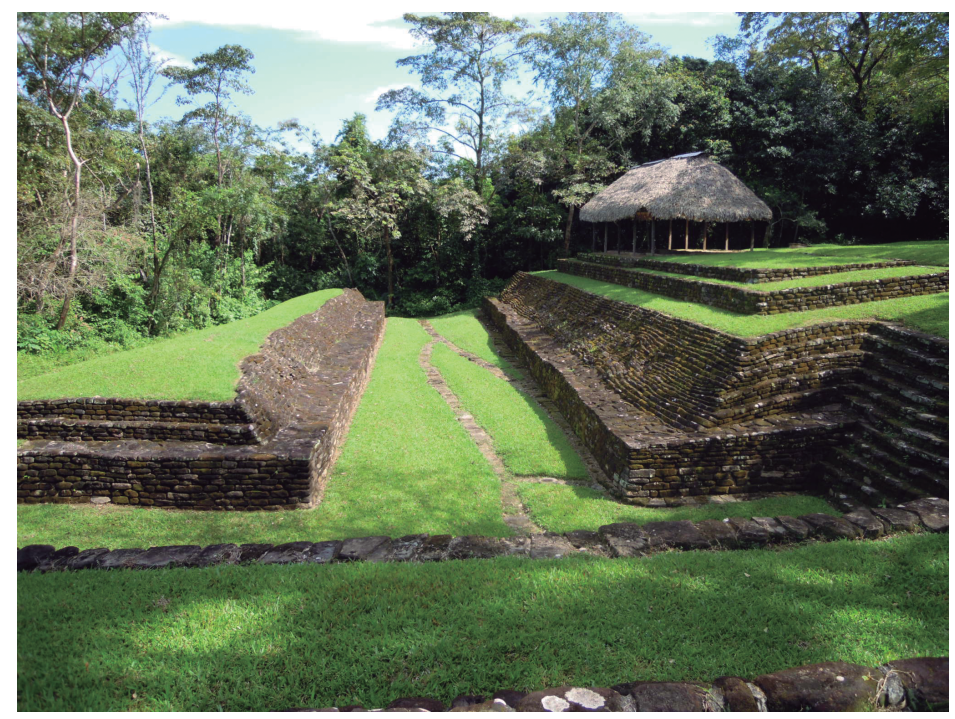

Figura 24. El juego de pelota de Malpasito con el baño de vapor (techado) sobre su lado. 


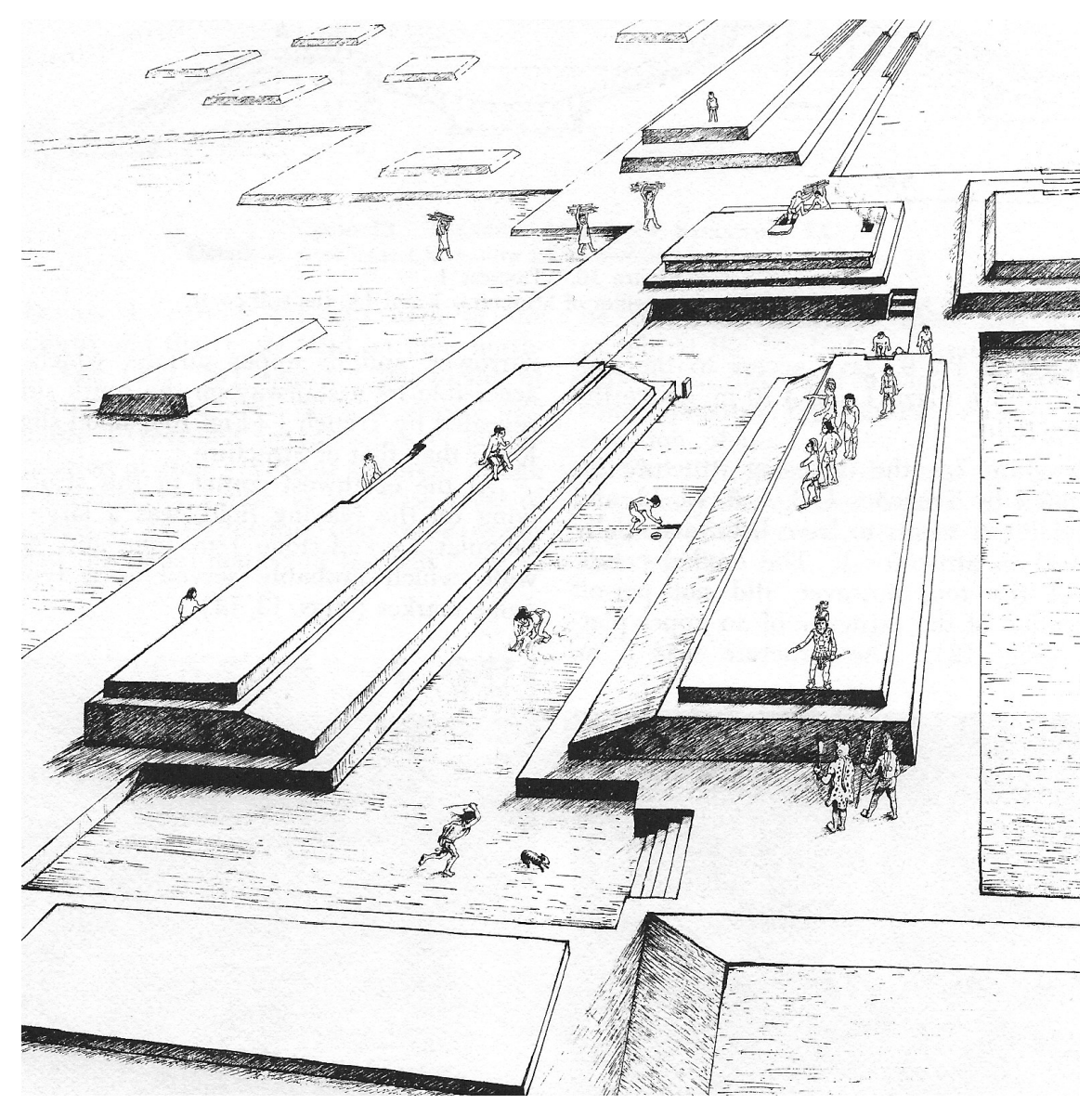

Figura 25. Imagen reconstructiva del juego de pelota de San Antonio con el baño de vapor en su cabecera (según Agrinier, 1969: 9).

No obstante se observan algunas diferencias desde el punto de vista funcional: en lo relativo al acceso, la antecámara de Malpasito presenta una escalinata formal de nueve escalones, en El Higo hay un solo escalón de acceso, mientras que en San Antonio el temazcal no presenta acceso visible, por lo que la entrada al espacio debía efectuarse por el techo, así como ocurría en el caso del más antiguo baño de vapor de Ocozocoautla. En ninguno de los casos se han encontrados agujeros de ventilación y solamente la estructura de San Antonio tuvo un sistema de desaguie.4 Las diferencias más notables se aprecian en cuanto a las

${ }^{4}$ Ya que en El Higo no se excavó la parte central de la sala de vapor, no se puede excluir que allí hubieran evidencias de un sistema de desagüe, aunque hay que remarcar que no se detectó desagüe hacia la entrada, hacia donde éstos se dirigen normalmente; ningún sistema de desagüe se menciona para Malpasito. 
formas de calentamiento: en el caso de Malpasito hay una cámara de combustión lateral separada del espacio principal (tal como ocurre en Chichén Itzá, Piedras Negras, Finca el Paraíso y Cimientos-Chustum, según Alcina, Ciudad e Iglesias, 1980: 115), en donde el fuego calentaba directamente la pared de la sala de vapor; en el caso de San Antonio no hay cámara de combustión, aunque la antecámara fue destinada a este uso en algún momento. Por último, en El Higo el fuego se encendía directamente en la sala de vapor (a menos que hubiera una cámara de combustión no excavada sobre el lado occidental), como se hizo también en San Antonio en algunas fases de su utilización.

Un elemento de especial interés es la presencia de grandes acumulaciones de fragmentos quemados de ollas al interior de la sala de vapor, tanto en San Antonio como en El Higo. La acumulación intencional de estos fragmentos es indudable y, por lo tanto, debemos suponer que se utilizaran como material destinado a retener el calor y sobre el cual verter el agua para producir el vapor. Una técnica análoga, especialmente útil en áreas donde predomina la piedra caliza (poco adecuada para ser calentada), ha sido detectada en Dzibichaltún (Andrews IV y Andrews V, 1980: 31-33), Los Cimientos (Rivero, 1987; Alcina Franch, 2000: 83) y posiblemente en Acanmul (Benavides y Ojeda, 2015: 146); la utilización de fragmentos de cerámica para proteger del calor las paredes de un baño de vapor se ha descrito en el baño de vapor N-1 de Piedras Negras (Cresson, 1938: 89). Si el uso de dicha técnica de calentamiento es explicable para el caso de El Higo, cuyas estructuras son de piedra caliza, no queda clara la razón de la diferencia de uso entre San Antonio y Malpasito, en donde las estructuras se edificaron con arenisca.

Sobre todo, no queda claro por qué, tanto en El Higo como en San Antonio, los fragmentos de ollas se dejaron entremezclados con los desechos de combustión sin proceder a la limpieza de la sala, llegando así a rellenar partes importantes del espacio interno a lo largo del tiempo. En El Higo el tamaño de la capa de fragmentos y su obvia deposición intencional permiten excluir que conformara una capa de recubrimiento de las paredes. El caso de San Antonio, en donde la acumulación de cerámica y desechos implicó frecuentes cambios en la ubicación del fuego excluye además que se trate de restos de ceremonias de terminación del baño de vapor. Es posible por lo tanto que la razón de un comportamiento aparentemente tan inexplicable fuera ligada a las normas rituales que debieron reglamentar el uso del baño de vapor.

La función eminentemente ceremonial de los tres baños de vapor monumentales es sugerida tanto por sus dimensiones excepcionales, que implican un uso colectivo por parte de grandes grupos, así como por su asociación preferencial con el juego de pelota. Baños de vapor asociados — directa o indirectamentecon canchas para el juego existen en varios sitios, entre ellos Toniná (Taladoire, 1975), Tikal (Taladoire, 1975: 265), Piedras Negras, Yaxchilán (Child, 2005: 163- 
164; Miller, 2013), Filobobos (Ortíz Butrón, 2001, 2005), ${ }^{5}$ Monte Albán (Taladoire, 1975), Xochicalco (Alcina, 2000: 78), Teotenango (Alcina, 2000: 78), Chichén Itzá, Tula (aunque en este caso el temazcal es más tardío que la cancha; Alcina, 2000: 77), Ranas en Querétaro (Mejía y Herrera, 2006; Mejía, 2016), El Piñón en Jalisco (Cabrera y López, 2007: 244, figura 9), Potrero de Guadalupe en Michoacán (Pereira 2010: 25-26) y Cihuatán en El Salvador (Olsen y Bertolucci, 2009: 44).

Varios autores (entre ellos Agrinier, 1966: 31; 1969: 16; Alcina, 2000: 77; Cuevas, 2004: 57-58; Child, 2005: 163) han propuesto que la relación del baño de vapor con la cancha de juego se debió a ceremonias de purificación que se realizaban antes del juego, así como lo sugieren también algunas fuentes coloniales e iconografías mayas de Chichén Itzá (Cepeda, 1972: 127-130; Miller 2013: 232).

A menudo se ha subrayado cómo la simbología del juego de pelota se hallaba estrictamente ligada a la idea de la transición entre el mundo terrestre y el inframundo, así como a la asociación entre la muerte/sacrificio y el nacimiento o renacimiento (por ejemplo, Schele y Friedel, 1991; Gillespie, 1991; Taladoire, 2000): en este sentido, la simbología inframundana y liminar del temazcal, percibido como lugar de nacimiento o renacimiento de seres humanos y extrahumanos (López Austin, 1980; Katz, 1993; Houston, 1996; Child, 2005, 2006, 2007; Miller 2013), bien pudiera justificar la asociación, tanto física como simbólica, entre baños de vapor y canchas para el juego de pelota. La ubicación preferencial de los juegos de pelota en las partes bajas de los sitios, común también en nuestra área de estudio y por ende compartida por los baños de vapor monumentales, quizás estuviese relacionada con la caracterización inframundana de ambos tipos de estructuras. ${ }^{6}$

Si las mencionadas connotaciones simbólicas son de carácter panmesoamericano, la difusión de la tipología específica de baños de vapor asociados a canchas de juego en el área zoque del Clásico Tardío-Terminal merece ser considerada con más detenimiento. Es notorio que existieron canchas de juego en el área mixe-zoque de la Depresión Central y de la costa pacífica desde el Preclásico, incluyendo —en el caso de Paso de la Amada, Chiapas - la más antigua hasta la fecha conocida en Mesoamérica (Hill, Blake y Clark, 1998; Hill y Clark, 2001). Sin embargo, en el área del oeste de Chiapas/sur de Tabasco que nos ocupa, existen solamente dos canchas de juego anteriores al Clásico Tardío, en Ocozocoautla (Agrinier, 1991: 177) y Miramar (Agrinier, 2000: 177), siendo en ambos casos el fechamiento inseguro. ${ }^{7}$ Por lo demás, todas las canchas de la región se remontan

${ }^{5}$ El temazcal de Filobobos, Veracruz, de forma circular, resalta por sus grandes dimensiones (diámetro aproximado de $8 \mathrm{~m}$ ), siendo el único comparable con los tres que aquí se discuten.

${ }^{6}$ Véase Battcock (2009) para interesantes observaciones sobre la relación entre el temazcal y la cancha de juego en los relatos nahuas sobre la muerte de Maxtla.

${ }^{7}$ Agrinier (1991: 177) describe la cancha de Ocozocoautla como del Clásico Temprano, pero sin haber realizado excavaciones en ella. Suponemos por lo tanto que el fechamiento se basa en la ocupación principal del sitio. Sin embargo, a lo largo de nuestras visitas al sitio de Ocozocoautla pudimos observar varias estructuras cuya tipología parece más bien del Clásico Tardío, lo cual sugiere que el 
al Clásico Tardío-Terminal (Agrinier, 1991: 180), con una total desaparición en la época Posclásica. ${ }^{8}$

En nuestra área de estudio predominan las canchas con cabezales cerrados, pero hay en realidad una gran variedad formal, cuyo caso más extremo es, sin duda, representado por la conocida cancha doble de San Isidro (Matos, 1966, 2000); una variabilidad análoga se observa en regiones cercanas, como la de Malpasito, donde la relevancia sociopolítica del juego está además confirmada por la abundancia de petrograbados con imágenes de canchas para el juego (Cuevas, 2004: 56-58).

El principio del Clásico Tardío coincidió sin duda con uno de los cambios más tajantes que se registran en la historia prehispánica de los zoques, marcado por la difusión de elementos culturales novedosos (cambios en el patrón de asentamiento, nuevo estilo arquitectónico, introducción de cerámicas de pastas finas, cambios en los patrones de prácticas rituales hipogeas, etcétera) que apuntan hacia estrechas relaciones con el área de la Costa del Golfo (Domenici, 2009, 2010; Domenici y Lee, 2012: 72-80; Domenici et al., 2013; Clark, 2014: 231-238). En este contexto, es evidente que la proliferación de canchas para el juego de pelota indica que el juego tuvo un importante papel en la nueva integración sociopolítica de toda el área zoque. Los baños de vapor monumentales asociados a las canchas, sin embargo, se concentran en un área limitada al oeste de Chiapas y sur de Tabasco, lo que sugiere que se trató de una innovación local: además de los tres casos aquí discutidos de San Antonio, Malpasito y El Higo, es probable que la misma asociación se repita en varios sitios no excavados, entre ellos El Tigre, López Mateos, ${ }^{9}$ El Ocote y Santa Laura, en la región de Malpaso (Agrinier, 1991: 182). ${ }^{10}$

La uniformidad y la concentración geográfica de los temazcales monumentales asociados a las canchas sugiere, por lo tanto, que una forma específica de juego de pelota, con sus rituales asociados, se haya desarrollado en el área zoque del

sitio tuviese también una ocupación de esta fase. El hecho de que la cancha tenga paredes de bloques careados de travertino sugiere que puede pertenecer al Clásico Tardío. En cuanto a la cancha de Miramar, la realización de trincheras en uno de sus montículos sacó a la luz material cerámico fechado entre el Preclásico Temprano y el Clásico Medio, lo cual simplemente establece un término post quem para su edificación (Agrinier, 2000: 177).

${ }^{8}$ La más cercana de las cuatro canchas posclásicas conocidas en la Depresión Central se encuentra en el sitio Ruiz, en la subregión de Acala (Agrinier, 1991: 194).

${ }^{9}$ El sitio de El Tigre es uno de los más impactantes y mejor preservados ejemplos de centros monumentales del Clásico Tardío-Terminal de El Ocote; dada su ubicación en la cabecera norte del juego de pelota, suponemos que la Estructura 9 local podría ser un baño de vapor. Análoga es la situación de la Estructura 9 de López Mateos, ubicada sobre el cabezal meridional del juego de pelota. En ambos casos, la relación de los supuestos temazcales con la cancha sería muy parecida a la del temazcal de San Antonio.

10 Otro caso interesante sería el del sitio MP-2, La Reforma, en donde una pequeña estructura cuadrangular (Estructura 1c) cierra el cabezal abierto del juego de pelota. Desafortunadamente, las excavaciones llevadas a cabo en el sitio antes de su inundación por la presa de Malpaso se limitaron a poner en luz parte de su muro exterior (Lowe, 1998: 53, figuras 17 y 18). 
oeste de Chiapas y sur de Tabasco. Fenómenos parecidos de difusión de diferentes formas de juego de pelota han sido observados a lo largo del periodo Clásico en el área culturalmente afín del centro-sur de Veracruz, donde también el juego de pelota reflejó importantes procesos de integración política y social (véase Daneels, 2008).

Bajo esta perspectiva, la nueva forma de juego y los rituales asociados desarrollados en el oeste de Chiapas/sur de Tabasco en el Clásico Tardío-Terminal parecen indicar que la difusión de nuevas prácticas rituales habría jugado un papel importante en la integración político-cultural de una región caracterizada por un patrón de asentamiento policéntrico y escasamente centralizado. Cabe resaltar que el periodo Clásico Terminal fue también un momento de auge de los baños de vapor en el área maya (Matarredona, 2014: 27; Benavides y Ojeda, 2015: 151152). Sin duda, la majestuosidad de los baños de vapor aquí descritos es un claro síntoma del periodo de extraordinario florecimiento y de gran innovación cultural que los zoques de Chiapas experimentaron en la parte tardía del periodo Clásico.

\section{Bibliografía}

Agrinier, Pierre

1966 "La casa de baños de vapor de San Antonio, Chiapas", Boletín del Instituto Nacional de Antropología e Historia, 25: 29-32.

1969 Excavations at San Antonio, Chiapas, Mexico. Provo: Brigham Young University (Papers of New World Archaeological Foundation, 76).

1991 "The Ballcourts of Southern Chiapas, Mexico", The Mesoamerican Ballgame, pp. 175-194, Vernon L. Scarborough y David D. Wilcox (eds.). Tucson: The University of Arizona Press.

1992 “El Montículo 1 de Ocozocoautla, Chiapas”, Antropología mesoamericana. Homenaje a Alfonso Villa Rojas, pp. 238-251, Víctor M. Esponda, Sophia Pincemin y Mauricio Rosas (comps.). Tuxtla Gutiérrez: Gobierno del Estado de Chiapas, Consejo Estatal de Fomento a la Cultura, Instituto Chiapaneco de Cultura.

2000 Mound 27 and the Middle Preclassic Period at Mirador, Chiapas, Mexico. Provo: Brigham Young University (Papers of the New World Archaeological Foundation, 58).

2014 Mound 1 at Ocozocoautla, Chiapas, Mexico. Gareth W. Lowe y John E. Clark (eds.). Provo: Brigham Young University (Papers of the New World Archaeological Foundation, 76).

Agrinier Pierre y John E. Clark

2014 "Mound 1 in Perspective", Mound 1 at Ocozocoautla, Chiapas, Mexico, pp. 8192, Gareth W. Lowe y John E. Clark (eds.). Provo: Brigham Young University (Papers of the New World Archaeological Foundation, 76). 
Alcina Franch, José

2000 Temazcalli. Higiene, terapéutica, obstetricia y ritual en el Nuevo Mundo. Sevilla: Consejo Superior de Investigaciones Científicas, Escuela de Estudios Hispanoamericanos.

Alcina Franch, José, Andrés Ciudad Ruiz y Josefa Iglesias Ponce de León

1980 "El 'temazcal' en Mesoamérica: evolución, forma y función”, Revista Española de Antropología Americana, X: 93-132.

Andrews IV, E. Wyllys y E. Wyllys Andrews V

1980 Excavations at Dzibichaltun, Yucatan, Mexico. New Orleans: Middle American Research Institute, Tulane University.

Battcock, Clementina

2009 "Aspectos simbólicos, representaciones y significaciones de las diferentes muertes de Maxtla: una propuesta de análisis", Estudios de Cultura Náhuatl, 40: 215-234.

Beals, Ralph L.

1945 Ethnology of the Western Mixe. Berkeley: University of California Publications in American Archaeology and Ethnology 42 (1).

Benavides Castillo, Antonio y Heber Ojeda Mas

2015 "Tres temazcales mayas: los casos de Acanmul, Edzná y Oxkintok”, Arqueología, 50: 142-156.

Bruhns, Karen Olsen y Paul E. Amaroli Bertolucci

2009 "An Early Postclassic Round Structure at Cihuatán, El Salvador", Arqueología Iberoamericana, 2: 35-45.

Cabrera García, María Teresa y Carlos López Cruz

2007 "The Shaft Tombs of El Piñon, Bolaños Canyon, State of Jalisco, Mexico", Ancient Mesoamerica, 18: 239-257. DOI: 10.1017/S0956536107000107.

Carrasco, Pedro

1946 “El temazcal”, México prehispánico, pp. 737-741, Jorge A. Vivó (ed.). México: E. Hurtado.

Cepeda Cárdenas, Gerardo

1972 "Dos construcciones rituales del juego de pelota Mesoamericano", Religión en Mesoamérica, XIII Mesa Redonda de la Sociedad Mexicana de Antropología, pp. 127-133, Jaime Litvak King y Noemí Castillo (eds.). México: Sociedad Mexicana de Antropología.

Child, Mark B.

2005 "The Symbolic Space of the Ancient Maya Sweatbath", Space and Spatial 
Analysis in Archaeology, pp. 157-167, E. Robertson (ed.). Alberta: University of Calgary Press.

2006 The Archaeology of Religious Movements: The Maya Sweatbath Cult of Piedras Negras, Guatemala, tesis doctoral, Yale University, New Haven.

2007 "Ritual Purification and the Ancient Maya Sweatbath at Palenque, Mexico", Recent Investigations at the Ancient Maya Site of Palenque, pp. 233-264, Damien Marken (ed.). Walnut Creek: Alta Mira Press.

Child, Mark B. y Jessica Child

2000 "Los baños de vapor de Piedras Negras, Guatemala”, XIII Simposio de Investigaciones Arqueológicas en Guatemala, 1999, pp. 885-900. Guatemala: Museo Nacional de Arqueología y Etnología, Ministerio de Cultura y Deportes, Instituto de Antropología e Historia, Asociación Tikal.

2001 "La Historia del baño de vapor P-7 en Piedras Negras, Guatemala", XIV Simposio de Investigaciones Arqueológicas en Guatemala, 2000, pp. 449-464. Guatemala: Museo Nacional de Arqueología y Etnología Ministerio de Cultura y Deportes, Instituto de Antropología e Historia, Asociación Tikal, Guatemala.

Clark, John E.

2014 "Notes on Culture History of Western Chiapas", A Brief Reconnaissance of Three Chiapas Municipalities, pp. 217-240, John E. Clark (ed.), con contribuciones de Ronald W. Lowe y John E. Clark. Provo: Brigham Young University (Papers of the New World Archaeological Foundation, 77).

Clark, John E. y Mary Pye

2011 "Revisiting the Mixe Zoque: A Brief History of the Preclassic Peoples of Chiapas", The Southern Maya in the Late Preclassic: The Rise and Fall of an Early Mesoamerican Civilization, pp. 25-45, Michael Love y Jonathan Kaplan (eds.). Boulder: University Press of Colorado.

Cresson, Frank M.

1938 "Maya and Mexican Sweat Houses", American Anthropologist, 40: 88-104. DOI: 10.1525/aa.1938.40.1.02a00090.

Cuevas Reyes, Francisco

1994 Informe del Proyecto Arqueológico Malpasito, Huimanguillo, Tabasco. Temporada 1993. Villahermosa: Instituto Nacional de Antropología e Historia, Centro Tabasco.

2004 "El juego de pelota de Malpasito, Huimanguillo, Tabasco", Arqueología, 33: 47-59.

Daneels, Annick

2008 "Ball Courts and Politics in the Lower Cotaxtla Valley: A Model to Understand Classic Central Veracruz", Classic Period Cultural Currents in Southern and Central Veracruz, pp. 197-223, Philip J. Arnold III y Christopher Pool (eds.). Washington D.C.: Dumbarton Oaks. 
Domenici, Davide

2006 "Investigaciones arqueológicas en el sitio de El Higo, Selva El Ocote, Chiapas”, Presencia zoque. Una aproximación multidisciplinaria, pp. 323-343, Dolores Aramoni, Thomas A. Lee y Miguel Lisbona (eds.). Tuxtla Gutiérrez: Universidad de Ciencias y Artes de Chiapas.

2009 "Continuidades, discontinuidades e interacciones interculturales en el desarrollo cultural prehispánico de la selva El Ocote, Chiapas", Medio ambiente, antropología, historia y poder regional en el occidente de Chiapas y el Istmo de Tehuantepec, pp. 137-154, Thomas A. Lee W., Davide Domenici, Víctor M. Esponda y Carlos Uriel Del Carpio (coords.). Tuxtla Gutiérrez: Universidad de Ciencias y Artes de Chiapas.

2010 "Patrones de uso ritual del espacio hipogeo en la Selva El Ocote (Chiapas)", VI Coloquio Bosch Gimpera. Lugar, espacio y paisaje en arqueología. Mesoamérica y otras áreas culturales, pp. 349-386. México: Universidad Nacional Autónoma de México, Instituto de Investigaciones Antropológicas.

Domenici, Davide y Thomas A. Lee Whiting

2012 "Classic and Postclassic Zoque Settlement Patterns and Ritual Practices along the Middle La Venta River", Arqueología reciente de Chiapas: Contribuciones del Encientro Celebrado en el $60^{\circ}$ Aniversario de la Fundación Arqueológica Nuevo Mundo, pp. 69- 86, Lynneth S. Lowe y Mary E. Pye (eds.). Provo: Brigham Young University (Papers of the New World Archaeological Foundation, 72).

Domenici, Davide, Lorenzo Zurla, Arianna Campiani, Nicoletta Maestri y Thomas A. Lee Whiting

2013 "Settlement Patterns and Household Archaeology in Selva El Ocote (Chiapas, Mexico)", Ocnus, 21: 237-258.

Finsten, Laura, Stephen A. Kowalewski, Charlotte A. Smith, Mark D. Borland y Richard D. Garvin

1996 "Circular Architecture and Symbolic Boundaries in the Mixtec Sierra, Oaxaca”, Ancient Mesoamerica, 7 (1): 19-35. DOI: 10.1017/S0956526100001267.

Foster, George M.

1969 "The Mixe, Zoque, and Popoluca”, Handbook of Middle American Indians, vol. 7, Ethnology, Pt. 1, pp. 448-477, Evon Z. Vogt (ed.). Austin: University of Texas Press.

Gaxiola González, Margarita

2001 "Un temazcal terapéutico en el barrio de talladores de obsidiana de Huapalcalco, Hidalgo", Arqueología, 26: 49-70.

Gillespie, Susan D.

1991 "Ballgames and Boundaries", The Mesoamerican Ballgame, pp. 317-345, Vernon L. Scarborough y David D. Wilcox (eds.). Tucson: University of Arizona Press. 
Groark, Kevin P.

1997 "To Warm the Blood, to Warm the Flesh: The Role of the Steambath in Highland Maya (Tzeltal-Tzotzil) Ethnomedicine”, Journal of Latin American Lore, 20 (1): 3-96.

Hammond, Norman, y Jeremy Bauer

2001 "A Preclassic Maya Sweatbath at Cuello, Belize”, Antiquity, 75 (290): 683-684. DOI: $10.1017 /$ S0003598X00089158.

Helmke, Christophe

2005 A Report of the 2005 Season of Archaeological Investigations at Pook's Hill, Cayo District, Belize, manuscrito en posesión del autor.

Helmke, Christophe y Jaime Awe

2010 "Hot Archaeology: An Ancient Maya Sweatbath at Pook's Hill", Current World Archaeology, 40: 38-43.

Hill, Warren D., Michael Blake y John E. Clark

1998 "Ball Court Design Dates Back 3,400 years", Nature, 392: 878-879. DOI: $10.1038 / 31837$.

Hill, Warren D. y John E. Clark

2001 "Sports, Gambling, and Government: America’s First Social Compact?", American Anthropologist, 103 (2): 331-345. DOI: 10.1525/aa.2001.103.2.331.

Houston, Stephen D.

1996 "Symbolic Sweatbaths of the Maya: Architectural Meaning in the Cross Group at Palenque, Mexico”, Latin American Antiquity, 7 (2): 132-151. DOI: $10.2307 / 971614$.

Ichon, Alain

1997 "A Late Postclassic Maya Sweathouse, Guatemala", American Antiquity, 42: 203-209. DOI: $10.2307 / 278981$.

Katz, Esther

1993 "El temazcal: entre religión y medicina”, III Coloquio de Historia de la Religión en Mesoamérica y los Andes, Barbro Dahlgren (comp.). México: Universidad Nacional Autónoma de México, Instituto de Investigaciones Antropológicas.

Koszkul, Wiesław y Jarosław Źrałka

2017 The Bedrock Precinct at Nakum and the Rituals of the Earliest Maya, ponencia presentada en la 22 ${ }^{\text {nd }}$ European Maya Conference. Malmö, Sweden, 15-16 Diciembre 2017.

Lipp, Frank J. 1991

The Mixe of Oaxaca. Religion, Ritual, and Healing. Austin: University of Texas Press. 
López Austin, Alfredo

1980 Cuerpo humano e ideología: las concepciones de los antiguos nahuas, México: Universidad Nacional Autónoma de México, Instituto de Investigaciones Antropológicas.

Lowe, Gareth W. y Pierre Agrinier

1960 Mound 1, Chiapa de Corzo, Chiapas, México. Provo: Brigham Young University (Papers of the New World Archaeological Foundation, 8).

Lowe, Lynneth S.

1998 El salvamento arqueológico de la presa de Mal Paso, Chiapas. Excavaciones menores. México: Universidad Nacional Autónoma de México, Instituto de Investigaciones Filológicas, Centro de Estudios Mayas.

Lowe, Lynneth S. y Carlos Álvarez Asomoza

2007 "Recent Explorations at the Postclassic Site of Los Cimientos de las Margaritas, Chiapas", Archaeology, Art, and Ethnogenesis in Mesoamerican Prehistory: Papers in Honor of Gareth W. Lowe, pp. 321-335, Lynneth S. Lowe y Mary E. Pye (eds.). Provo: Brigham Young University (Papers of the New World Archaeological Foundation, 68).

Mason, Alden J.

1935 "Mexican and Mayan Sweat-Baths", Philadelphia University Museum Journal, 6: 65-69.

1960 The Terrace to North of Mound 13, Chiapa de Corzo, Chiapas, Mexico. Provo: Brigham Young University (Papers of the New World Archaeological Foundation, 11).

Matarredona Desantes, Nuria

2014 "La arquitectura del baño de vapor en la cultura maya”, Estudios de Cultura Maya, XLIV: 13-40. DOI: 10.19130/iifl.ecm.2014.44.117.

Matos Moctezuma, Eduardo

1966 "Un juego de pelota doble en San Isidro, Chiapas”, Boletín del Instituto Nacional de Antropología e Historia, 25: 36-37.

2000 "El Juego de pelota con doble cancha de San Isidro", Arqueología Mexicana, VIII (44): 42-45.

McKee, Brian R.

1997 "La Estructura 9 de Joya de Cerén: Un temazcal del Periodo Clásico", X Simposio de Investigaciones Arqueológicas en Guatemala 1996, pp. 237-249, Juan Pedro Laporte y Héctor L. Escobedo (eds.). Guatemala: Museo Nacional de Arqueología y Etnología, Ministerio de Cultura y Deportes, Instituto de Antropología e Historia, Asociación Tikal. 
Mejía Pérez Campos, Elizabeth

2016 "Las canchas de juego de pelota en Toluquilla, Querétaro", Arqueología Mexicana, 51: 7-30.

Mejía Pérez Campos, Elizabeth y Alberto Herrera Muñoz

2006 "El Sur de la Sierra Gorda: Ranas y Toluquilla”, Arqueología Mexicana, XIII (77): 38-41.

Miller, Catherine Annalisa

2013 "Earth, Water, Sky. The Liminal Landscape of the Maya Sweatbath", tesis para obtener el grado de Philosophy Doctor. Blacksburg: Virginia Polytechnic Institute and State University.

Ortiz Butrón, Agustín

2001 "Sweatbaths", The Oxford Encyclopedia of Mesoamerican Cultures, 3, p. 176, David Carrasco (ed.). Oxford: Oxford University Press.

2005 "El temascal arqueológico", Arqueología Mexicana, XIII (74): 52-53.

Pereira, Grégory

2010 "Arqueología de un lugar de pasaje hacia el inframundo", Trace, 58: 19-28.

Rivero Torres, Sonia

1987 Los Cimientos, Chiapas. A Late Classic Maya Community. Provo: Brigham Young University (Papers of the New World Archaeological Foundation, 51).

Satterthwaite, Linton

1952 Piedras Negras Archaeology: Architecture. Part V: Sweathouses. Philadelphia: University Museum of Pennsylvania.

2005 "Sweathouses", Piedras Negras Archaeology, 1931-1939, pp. 241-317, John M. Weeks, Jane A. Hill y Charles Golden (eds.). Philadelphia: University of Pennsylvania, Museum of Archaeology and Anthropology.

Schele, Linda y David Freidel

1991 "The Courts of Creation: Ballcourts, Ballgames, and Portals to the Maya Otherworld", The Mesoamerican Ballgame, pp. 289-315, Vernon L. Scarborough y David D. Wilcox (eds.). Tucson: University of Arizona Press.

Servain, Frédérique

1986 "Tentative de classification des bains de vapeur en Mésoamérique”, Trace, 9: 39-50.

Taladoire, Eric

1975 "Les bains de vapeur et les systèmes d'eau dans leur rapport avec les terrains de jeu de balle", Actas del XLI Congreso Internacional de Americanistas, pp. 262-269. México: Sociedad de Americanistas.

2000 "El juego de pelota mesoamericano: origen y desarrollo", Arqueología Mexicana, VIII (44): 20-27. 
Thomas, Norman D.

1974a Envidia, brujería y organización ceremonial. Un pueblo zoque. México: Secretaría de Educación Pública.

1974b The Linguistic, Geographic, and Demographic Position of the Zoque of Southern Mexico. Provo: Brigham Young University (Papers of the New World Archaeological Foundation, 36).

Villa Rojas, Alfonso

1973 "Notas sobre los zoques de Chiapas, México", América Indígena, XXXIII (4): 1031-1070.

Zurla, Lorenzo

2003 "Scavo e documentazione di un complesso architettonico in ambiente carsico-tropicale. Il Settore I di El Higo, Chiapas, Messico", tesis de maestría en Arqueología. Bolonia: Universidad de Bolonia.

2009 "Excavación del Sector I de El Higo, Ocozocoautla, Chiapas: metodología e interpretación”, Medio ambiente, antropología, historia y poder regional en el occidente de Chiapas y el Istmo de Tehuantepec, pp. 155-162, Thomas A. Lee W., Davide Domenici, Víctor M. Esponda y Carlos Uriel Del Carpio (coords.). Tuxtla Gutiérrez: Universidad de Ciencias y Artes de Chiapas (Colección Selva Negra). 